\title{
Recent Advances and Applications in Paper-Based Devices for Point-of-Care Testing
}

\author{
Yue Hou ${ }^{1}$. Cong-Cong $\mathrm{Lv}^{1} \cdot$ Yan-Li Guo ${ }^{1} \cdot$ Xiao-Hu Ma ${ }^{1} \cdot$ Wei Liu ${ }^{1} \cdot$ Yan Jin $^{1} \cdot$ Bao-Xin $\mathrm{Li}^{1} \cdot$ Min Yang ${ }^{1} \cdot$ Shi-Yin Yao $^{1}$
}

Received: 4 September 2021 / Accepted: 16 November 2021 / Published online: 13 January 2022

(c) The Nonferrous Metals Society of China 2022

\begin{abstract}
Point-of-care testing (POCT), as a portable and user-friendly technology, can obtain accurate test results immediately at the sampling point. Nowadays, microfluidic paper-based analysis devices ( $\mu$ Pads) have attracted the eye of the public and accelerated the development of POCT. A variety of detection methods are combined with $\mu$ Pads to realize precise, rapid and sensitive POCT. This article mainly introduced the development of electrochemistry and optical detection methods on $\mu$ Pads for POCT and their applications on disease analysis, environmental monitoring and food control in the past 5 years. Finally, the challenges and future development prospects of $\mu \mathrm{Pads}$ for POCT were discussed.
\end{abstract}

Keywords Paper-based analysis device $\cdot$ Point-of-care testing $\cdot$ Detection methods $\cdot$ Review

\section{Introduction}

Point-of-care testing (POCT) is a low-cost, user-friendly, and portable technology that uses fast and convenient analytical instruments to obtain test results immediately at the sampling point [1]. By using low-volume of samples, POCT can be realized in hospitals, clinics, doctor's offices or homes [2]. Compared to central laboratory testing [3], POCT system has advantages of immediate turn-around time, easy-touse format, high sensitivity and accuracy.

Nowadays, the technological challenge in the field of microfluidic paper-based analytical devices ( $\mu$ Pads) is the main support for POCT systems. $\mu$ Pads are also known as lab-on-a-chip (LOC), which are proposed by Whitesides' group in 2007 [4]. It miniaturizes the principal use of chemistry, biology and other laboratories to a small space of paper. It is an analytical platform that integrates the function of injection [5], reaction [6], separation [7] and detection [8] into paper by building hydrophilic and hydrophobic channels. The sample and reaction solution are driven by the capillary force of paper. $\mu$ Pads have the advantage of

Wei Liu

weiliusnnu@snnu.edu.cn; weiliu@126.com

1 Key Laboratory of Analytical Chemistry for Life Science of Shaanxi Province, School of Chemistry and Chemical Engineering, Shaanxi Normal University, Xi' an 710062, China low production cost, simple method, easy processing, good biocompatibility, and small reagent consumption. Then the development of $\mu$ Pads has shown exponential growth in recent years [9].

$\mu$ Pads have been prepared by a variety of methods, such as photoetching[10, 11], inkjet printing [12], wax printing [13], laser processing [14], plasma processing [15], cutting [16], one-step plotting technology [17], flexographic printing [18], and stereoscopic printing [19]. We all know that hydroxyl groups on the paper are simple to be modified [20, 21]. So hydrophilic and hydrophobic regions can be easily constructed on the paper surface. Then the paper permeability and surface reaction activity are changed to create reaction channels for the migration, storage and reaction of reagents [22]. The $\mu$ Pads prepared by these advanced fabrication methods greatly expand the potential applications because paper can be used as the fine substrate for POCT devices. High-throughput determination of the content of multiple components in samples can be realized on $\mu$ Pads. Also, $\mu$ Pads provide a good platform for sample pretreatment, reagent transportation, mixing, separation and detection and other analytical functions [23-25].

As fast response rate and high sensitivity are the main demands for POCT, the detection system is vital for signal acquisition. So far, various detection technologies such as electrochemistry (EC), electrochemiluminescence (ECL), colorimetry, fluorescence (FL), surface-enhanced Raman scattering (SERS) and chemiluminescence (CL) have been 
assembled on $\mu$ Pads [26]. Honestly, each detection method has its advantages and drawbacks. Some optical detection methods use light sources as delivery or collection media to obtain signals. Because of acceptable sensitivity and response speed, these optical methods have become potential candidate technologies for $\mu \mathrm{Pads}$ [27]. While the size of optical equipments such as lasers, spectrophotometers, charge-coupled devices (CCDs) and photomultiplier tubes (PMTs) make it difficult to integrate on $\mu$ Pads. Then the application of optical methods for POCT is relatively limited [28]. Compared with optical detection, electrochemical methods can get rid of the dependence on optical-based techniques. Through selection of electrode material and electrochemical technique, electrochemical detection was realized with fast response and high sensitivity [29]. Nowadays, to enrich these detection methods and achieve sensitive and accurate signal out-put, various micro- and nano-materials with different signal transduction mechanisms, such as metal nanoparticles [30,31], metal oxide $[32,33]$, graphene or graphene oxide [34, 35], quantum dots $[36,37]$, hybrid materials $[38,39]$ and metal-organic frameworks [40-42] have brought new breakthroughs in the design of new paper-based sensors. In addition, signal readers tend to be miniaturized. Optical and electric signals can be read-out by portable devices like smartphone and electric watch [43, 44]. Therefore, combined with multiple detection technologies based on diverse sensing materials and portable signal readers, the POCT was realized on $\mu$ Pads and applied in the fields of disease analysis [45-48] (biological fluids like whole blood, serum, sweat, tears, urine, saliva, cells, viruses), environmental monitoring [49, 50] (water, gas, soil) and food control [51].

Therefore, considering that detection methods are crucial for paper-based POCT devices, it is essential to review and compare different existing detection methods on $\mu$ Pads. This article mainly introduces the development in the integration of detection methods on $\mu$ Pads in the past 5 years. Various detection methods including EC, ECL, colorimetry, FL, SERS and CL are applied on disease analysis, environmental monitoring and food control field. Moreover, the advantages and disadvantages of these optical detection methods are compared. Finally, the challenges and future development prospects of paper-based analytical devices for POCT are discussed. Although the portability of $\mu$ Pads makes them widely used, there is still a great room for improvement in stability and detection sensitivity.

\section{Electrochemical Detection Methods}

\subsection{Electrochemical Method}

Electrochemical (EC) method has been widely used to convert a biological or chemical event to an electronic signal. This detection method has been reported to integrate on the $\mu$ Pads by Henry's group [29]. EC combined with $\mu$ Pads is known as electrochemical paper-based analytical devices (ePads). EPads are always sensitive and have quick response, which have been a main support at the POCT. Recent examples of applications are reviewed here to demonstrate the potential of ePads in environmental monitoring [49] and biomedical analysis [52-78] as well as food safety control [79-81] field.

\subsubsection{Environmental Monitoring}

Metal ions have been measured by ePads in Silva-Neto's report [49]. A "plug-and-play" (PnP) assembly for multiplexed detection of $\mathrm{Fe}, \mathrm{Ni}, \mathrm{Cu}, \mathrm{Zn}, \mathrm{Cd}$ and $\mathrm{Pb}$ in river water samples with screen-printed ePad was described. The device had good selectivity and aspirated sample volume can be managed well. The detection values for these metal ions were in the range of $0.9-10.5 \mu \mathrm{g} / \mathrm{L}$.

\subsubsection{Biochemical Assays}

As reported by Liang [52], a wearable electrochemical sensor using three-dimensional paper-based microfluidic electrochemical device (3D-PMED) for real-time monitoring of potassium ion $\left(\mathrm{K}^{+}\right)$in sweat was fabricated. The 3D-PMED integrated a screen-printed $\mathrm{K}^{+}$-selective sensor with limit of detection (LOD) of $132 \mathrm{mmol} / \mathrm{L}$. Also, per decade of $\mathrm{K}^{+}$for the electrode response potential was $61.79 \mathrm{mV}$. In 2017, a parylene C-coated newspaper (PC-paper) was developed by patterning of metal layers. These chemically stable electrochemical platforms were applied to the detection of electrolyte cations, like $\mathrm{H}^{+}$and $\mathrm{K}^{+}$[53]. EC method was used for investigating the fluid dynamics. Such as a 2-layer $\mu$ Pad was used for increasing the flow rate through precise control of the channel height. A ferrocene complex was analyzed and anodic stripping detection of cadmium with fivefold enhancement signal was performed on this ePad [54].

Based on electrochemical methods, small molecules can also be detected on $\mu$ Pads. For example, as reported by Ming's work [55], 17 $\beta$-estradiol (E2) was detected by a folding aptasensor platform with the label-free electrochemical detection method. Amine-functionalized single-walled carbon nanotube/ new methylene blue/ AuNPs were adopted for immobilizing the aptamer. The calibration curve showed a linear range from $10 \mathrm{pg} / \mathrm{mL}$ to $500 \mathrm{ng} / \mathrm{mL}$ and a LOD of $5 \mathrm{pg} / \mathrm{mL}$. In 2018, Sales and his team have fabricated an ePad by applying the homemade conductive inks for structuring the electrodes. Square wave voltammetry (SWV) method was used to detect 3-nitrotyrosine (3-NT). As for the sensitivity of the sensor, a low LOD of $49.2 \mathrm{nmol} / \mathrm{L}$ of $3-\mathrm{NT}$ can be obtained [56]. In Wang's work, they reported a papersupported photoelectrochemical sensing platform based on surface plasmon resonance enhancement for real-time $\mathrm{H}_{2} \mathrm{~S}$ 
determination. $\mathrm{H}_{2} \mathrm{~S}$ can induce surface plasmon resonance (SPR) enhancement between Ag NPs and CdS QDs [57].

There are also some works about glucose detection [58-62]. Chaiyo's group have introduced an ePad for the non-enzymatic detection of glucose in honey, white wine and human serum. The screen-printed carbon electrode was modified by cobalt phthalocyanine, grapheme and an ionic liquid (CoPc/G/IL/SPCE). The modified electrode on ePads had excellent electrocatalytic activity towards glucose in a wide calibration curve [58]. Glucose can also be detected by a wearable platinum sensor in Sarwar team's work [59]. As reported by Cinti's group [60], the filter paper was used as a container for reactions. Prussian Blue Nanoparticles (PBNPs) were produced on filter paper and then a reagentless electrochemical point-of-care device using glucose oxidase for glucose detection was developed with the concentration ranging up to $25 \mathrm{mmol} / \mathrm{L}(450 \mathrm{mg} / \mathrm{dL})$. Cellulose nanofibers (CNs) were performed on ePad for glucose measurement in blood samples [61], as shown in Fig. 1a. First, the electrospinning method was used for preparing cellulose acetate (CA) nanofibers. Then, in alkaline solution, the paper layer was changed to cellulose by deacetylation. The paper was treated with trimethyl chitosan (TMC) to obtain a smooth and continuous CNs layer. A thick layer of $\mathrm{Au}$ was sputtered on the TMC/CNs substrate and then reduced graphene oxide ( $\mathrm{rGO}$ ) was used to modify the working electrode. At last, the immobilization of glucose oxidase was performed on the CNs layer. The ePad has a linear range of 3.3-27.7 $\mathrm{mmol} / \mathrm{L}$ for glucose with a LOD of $0.1 \mathrm{mmol} / \mathrm{L}$. By converting electrochemical signals into optical readouts, Xu's group showed a closed bipolar electrode (CBE)-based two-cell electrochromic device for detection of lactate, glucose and uric acid [62]. A specific oxidase was coupled to the analytical cell color change, which is related to the concentration of metabolites.

In Li's review [63], they introduced the types of neurotransmitters and biological sample sources which were used for neurotransmitter detection and then reviewed the traditional fabrication technologies and modification methods for paper-based electrochemical POCT devices. In Lu's work [64], ePad was used for human immunodeficiency virus (HIV) DNA detection with methylene blue (MB) as a redox indicator. A paper-based electrode was made by using nickel metal-organic framework (Ni-MOF) composite/Au

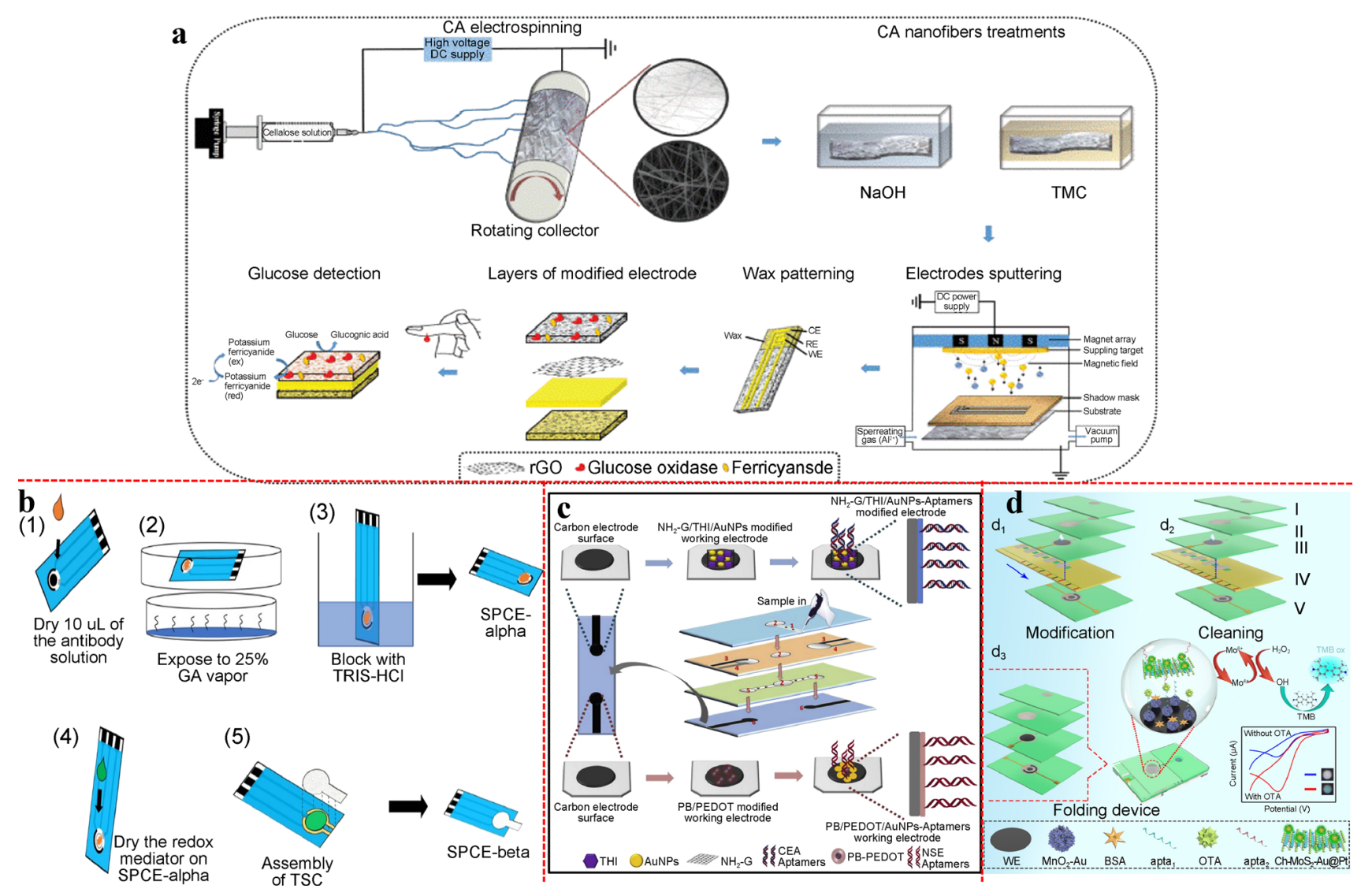

Fig. 1 Some examples for EC detection. a Schematics of glucoseePAD with different fabrication method for glucose detection [61]; b Schematic illustration of screen printed carbon electrodes [70]; c Fabrication and modification process of the multi-parameter ePAD for the detection of CEA and NSE [73]; d Illustration of the whole procedures and sensing principle for OTA determination [79] 
nanoparticles/carbon nanotubes/polyvinyl alcohol (Ni-Au composite/CNT/PVA). Ni-Au composite/CNT/PVA can achieve interactions between MOF and single-stranded DNA. Then a higher loading of the probe DNA was made. Peak current varied with the concentration of HIV DNA. The device sensed well in a linear range of $10 \mathrm{nmol} / \mathrm{L}-1 \mu \mathrm{mol} / \mathrm{L}$ and a low detection limit of $0.13 \mathrm{nmol} / \mathrm{L}$. Narang et al. fabricated an ePad combined with $\mathrm{Zn}-\mathrm{Ag}$ nanoblooms to detect herpes [65]. In infected patient samples, the ePad showed optimum current response in two linear ranges of $113-10^{3}$ and $3 \times 10^{5}-10^{6}$ copies $/ \mathrm{mL}$ with LOD of 97 copies $/ \mathrm{mL}$. In Cinti's work [66], printed electrochemical platforms were performed for ssDNA and dsDNA detection. The methylene blue (MB)-tagged TFO probes were coated on the working electrode. Then, TFO probes were fabricated on ePad and then dsDNA sequence can be detected in serum samples with the LOD of $7 \mathrm{nmol} / \mathrm{L}$.

In recent years, immunoassay has been used for the detection of antigens such as biomarkers. For example, in 2019, Qi's [67] team synthesized in-situ molecularly imprinted polymers (MIPs) on movable valve microfluidic paper-based electrochemical device (Bio-MIP-ePADs) for clinical detection of carcinoembryonic antigen (CEA) based on the strategy of antibody-free biomarker analysis with the detection range of $1.0-500.0 \mathrm{ng} / \mathrm{mL}$, and the detection limit could be achieved at $0.32 \mathrm{ng} / \mathrm{mL}$. Kaushik's group [68] proposed an electrochemical immunosensing platform for Ebola virus (EBOV) detection at $\mathrm{pmol} / \mathrm{L}$ concentration within $40 \mathrm{~min}$. It was a cost-effective, rapid, sensitive and selective sensor to detect Ebola virus disease (EVD) at point-of-care (POC). Cao's group [69] developed a sensitive immune method for human chorionic gonadotropin (HCG) detection on paperbased microfluidic device. Alkaline phosphatase combined secondary antibody (ALP-IgG) with functionalized gold nanoparticles was used as the signal antibody label. The hydrophilic test zones of the aldehyde-functionalized screen-printed electrodes (SPEs) were biofunctionalized with capture antibodies (Ab1). And the LOD of human chorionic gonadotropin (HCG) was $0.36 \mathrm{mIU} / \mathrm{mL}$. Honikel's group [70] provided a paper-based sensing platform by immobilizing different antibodies (antilactoferrin (Lfn) or anti-immunoglobulin $\mathrm{E}(\mathrm{IgE})$ ) onto screen-printed carbon electrodes. The LODs were $0.05 \mathrm{mg} / \mathrm{mL}$ and $40 \mathrm{ng} / \mathrm{mL}$ for Lfn and IgE, respectively (Fig. 1b). Li's team [71] developed a microfluidic paper-based biosensor integrated with zinc oxide nanowires ( $\mathrm{ZnO} N W s$ ) for rabbit immunoglobulin $\mathrm{G}(\mathrm{IgG})$ and the immunodeficiency virus p24 antigen detection. The whole procedure just took less than $25 \mathrm{~min}$. The ePad was performed for detecting rabbit immunoglobu$\operatorname{lin} \mathrm{G}(\mathrm{IgG})$ in phosphate-buffered saline with the LOD of $60 \mathrm{fg} / \mathrm{mL}$ and the immunodeficiency virus p24 antigen in human serum with the LOD of $300 \mathrm{fg} / \mathrm{mL}$. Wang's group [72] developed a label-free paper-based electrochemical immunosensor by using screen-printed working electrode (SPWE) to detect carcinoembryonic antigen (CEA). Amino functional grapheme $\left(\mathrm{NH}_{2}-\mathrm{G}\right)$ /thionine (Thi)/gold nanoparticles (AuNPs) nanocomposites were synthesized to raise the detection sensitivity. In 2019, Wang's team [73] fabricated the paper-based device by wax printing and screen-printing method. The device enabled the functions of sample filtration and auto injection. Amino functional graphene (NG)Thionin (THI)- gold nanoparticles (AuNPs) and Prussian blue (PB)- poly (3,4- ethylenedioxythiophene) (PEDOT)AuNPs nanocomposites were synthesized to modify the working electrodes not only for promoting the electron transfer rate, but also for immobilization of the CEA and NSE aptamers. A multi-parameter aptasensor on ePad for simultaneous detection of CEA and neuron-specific enolase (NSE) in a clinical sample was established. The ePad exhibited good linearity in ranges of $0.01-500 \mathrm{ng} / \mathrm{mL}$ for CEA and 0.05-500 ng/mL for NSE, respectively (Fig. 1c). Micropipette-tip immunoelectroanalytical platform coupled with staple-based paper device was established. Anti-tissue transglutaminase was detected with immunoassays performing in the polypropylene micropipette tips [74]. The platform was very promising for decentralized analysis. Besides, Zheng's group [75] fabricated a porous structure of AuNP-modified paper working electrode (Au-PWE) as a sensor substrate with a feature of all-round conductivity and plenty of active sites favoring biological ligand attachment, which was used to detect CEA and prostate-specific antigen (PSA) in enzyme-free condition. Wei's group [76] fabricated gold nanoparticles (AuNPs)/reduced graphene oxide (rGO)/ thionine (THI) nano composites as working electrodes for sensitive detection of PSA. THI was used as the electrochemical mediator to transduce the biological recognition between DNA aptamer and PSA. The linear range for PSA was $0.05-200 \mathrm{ng} / \mathrm{mL}$ with the LOD of $10 \mathrm{pg} / \mathrm{mL}$.

Additionally, severe acute respiratory syndrome coronavirus 2 (SARS-CoV-2) became a global pandemic outbreak in 2019. Yakoh's group developed a label-free paper-based electrochemical immunosensor for immunoglobulin detection against SARS-CoV-2 without the specific requirement of an antibody [77]. The principle was that the presence of SARS-CoV-2 antibodies would interrupt the redox conversion of the redox indicator. Then the signal decreased. This sensor was proven to be effective in real clinical sera from patients. West Nile virus can be measured with a LOD of 10.2 particles in $50 \mu \mathrm{L}$ of cell culture media by Channon's group [78] on an ePad with Au electrodes.

\subsubsection{Food Safety Control}

In Zhang's work [79], Ochratoxin A (OTA) was used as the model for an ePad immunoassay. Functionalized $\mathrm{MoS}_{2}-\mathrm{Au} @$ $\mathrm{Pt}\left(\mathrm{Ch}-\mathrm{MoS}_{2}-\mathrm{Au} @ \mathrm{Pt}\right)$ was produced to immobilize label 
aptamer (apta2) for signal amplification. The Ch-MoS $2-\mathrm{Au} @$ Pt-apta2 had the function of specific biorecognition and can be the catalyst for $\mathrm{H}_{2} \mathrm{O}_{2}$ reduction reaction. Then EC signal can be produced on ePad. As hydroxyl radicals can be produced in the reaction and induce TMB to change color, a colorimetric method was also established for OTA detection. So the dual-mode detection for OTA was obtained in the linear ranges of $0.1-200 \mathrm{ng} / \mathrm{mL}$ and $200-1 \times 10^{-4} \mathrm{ng} / \mathrm{mL}$ for visual and EC detection, respectively (Fig. 1d). DNA purification testing was performed on a micro ePad for foodborne pathogens detection. The whole procedure can be performed in half an hour and Escherichia was successfully detected [80]. Writing fabrication method on ePad was reported by Li's group [81]. The writing can be performed for the microfluidic channels and electrodes by two commercial pens. The hydrophobic part was written by a wax pen and electrodes were produced by a conductive-ink pen. The writing ePad was used to detect Salmonella typhimurium DNA by dual mode methods (colometry and EC), LODs of $1 \mathrm{nmol} / \mathrm{L}$ and $1 \mathrm{mmol} / \mathrm{L}$, respectively.

\subsection{Eelectrochemiluminescence (ECL)}

In order to maintain the advantages of paper devices, such as easy qualification and development, suitable detection techniques are required [82]. ECL is one of the most versatile analytical methods, due to its high sensitivity and signal-tonoise ratio. As examples, recent works have been performed on paper-based ECL devices to detect miRNA. Zhou et al. presented a portable ECL chip driven by CRISPR/Cas13a, which could be activated by target miRNA. Then, it triggered the subsequent exponential amplification with LOD as low as $1 \times 10^{-15} \mathrm{~mol} / \mathrm{L}$ of miRNA-17 [83]. Tumor cells can cause different degrees of harm to the human body. Therefore, the rapid detection of tumor cells using paper-based devices is important for clinical diagnosis. In Ge's work, AuPd nanoparticles (NPs) were used as a carrier and catalyst for luminol- $\mathrm{H}_{2} \mathrm{O}_{2}$ system. With the releasing of $\mathrm{H}_{2} \mathrm{O}_{2}$ from target cells, MCF-7 can be detected in the range of $1.5 \times 10^{2}-2.0 \times 10^{7}$ cells $/ \mathrm{mL}$ and LOD of 40 cells $/ \mathrm{mL}$ [84] (Fig. 2a). Similarly, Yang's work used semicarbazide and nano-silver as dual enhancers, and multi-branched doublestranded DNA nanowires (MBdsDNA) as carriers to detect tumor cells MCF-7, CCRF-CEM, HeLa, and K562 [85]. MCF-7's detection range and LOD were similar to that of Ge's work. Besides, paper-based ECL devices can be used for analysis of metal ions. As reported by Huang's work, due to $\mathrm{Ni}^{2+}$ and $\mathrm{Hg}^{2+}$ have quenching effects on ABEI's ECL emission, they first made an ECL sensor with repeated automatic cleaning of the working electrode to detect heavy metals [86] (Fig. 2b). The detection of cancer biomarkers can make judgments on course of disease, the existence and prognosis of the tumor cells. Sun has developed a rotating $\mu \mathrm{Pad}$ for multi-step ECL immunoassay of CEA and Prostate specific antigen (PSA) with the advantages of reusable rotary valve and short response time [87]. In addition, based on the DNA Walker's strand displacement reaction and the catalysis of DNA-Pt/CuTNFs [88], an enhanced luminol ECL signal was obtained to detect streptavidin with a low detection limit of $33.4 \mathrm{fmol} / \mathrm{L}$ (Fig. 2c). A diode was coupled on an ePad, which can dramatically enhance the signal intensity in Qi's work [89]. By using gold electrode array and an electromagnetic receiver coil, the ECL for detection of $\mathrm{H}_{2} \mathrm{O}_{2}$ can be on a par with photomultiplier tube (PMT)based results. The high sensitivity with the linear range of $10 \mathrm{nmol} / \mathrm{L}$ to $1 \mathrm{mmol} / \mathrm{L}$ was obtained. Moreover, paperbased ECL devices could be used for analysis of organic and inorganic compounds and other substances [90-103] involving various scientific fields such as environment monitoring, biochemical assay, food safety, and so on (as shown in Table 1). Then the paper-based microfluidic system [104] has great application potentials.

However, the above electrochemical method needs electrode couples on $\mu \mathrm{Pad}$. Electrode fabrication is a crucial step to fabricate. The power should be added on the device. Some electrodes which were used on $\mu \mathrm{Pad}$ still cannot have the performance in comparison to conventional metallic electrodes. Some other optical detection methods are shown below for $\mu \mathrm{Pad}$.

\section{Optical Detection Methods}

\subsection{Colorimetric Detection}

$\mu$ Pads with simple user interpretation and instruments are desired for POCT. Colorimetric detection is the primary technique applied in $\mu \mathrm{Pads}$, because color intensity can be realized easily by an ultraviolet-visible (UV-vis) spectrophotometer. Until now, it is widely applied in analysis of inorganic ions [105-114], biomedicals and proteins [115-122], nucleic acid and drugs [123-136], etc.

\subsubsection{Environmental Monitoring}

Colorimetric detection gets great potential applications in environmental monitoring. Generally, direct colorimetric detection can be measured by comparing the color intensity of the reaction spots with the standard colors [137]. For example, $\mathrm{Cu}^{2+}$ reacted with 3-(5-hydroxy-4carboxyphenylimino)-5-fluoroindol-2(H)one (HCFI) reagent to obtain a colored complex. Then a miniaturized spots patterned commercial book-paper was developed for $\mathrm{Cu}^{2+}$ detection as low as $1 \times 10^{-3} \mu \mathrm{g} / \mathrm{mL}$ [105]. In 2019, a silver triangular nanoplate (AgTNP)-modified paper strip was selectively used for detection of iodine. The 
$\mathbf{a}$

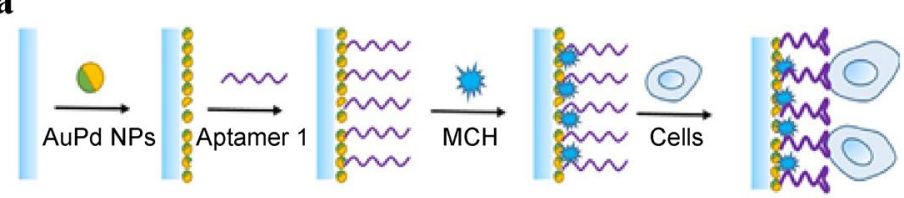

b
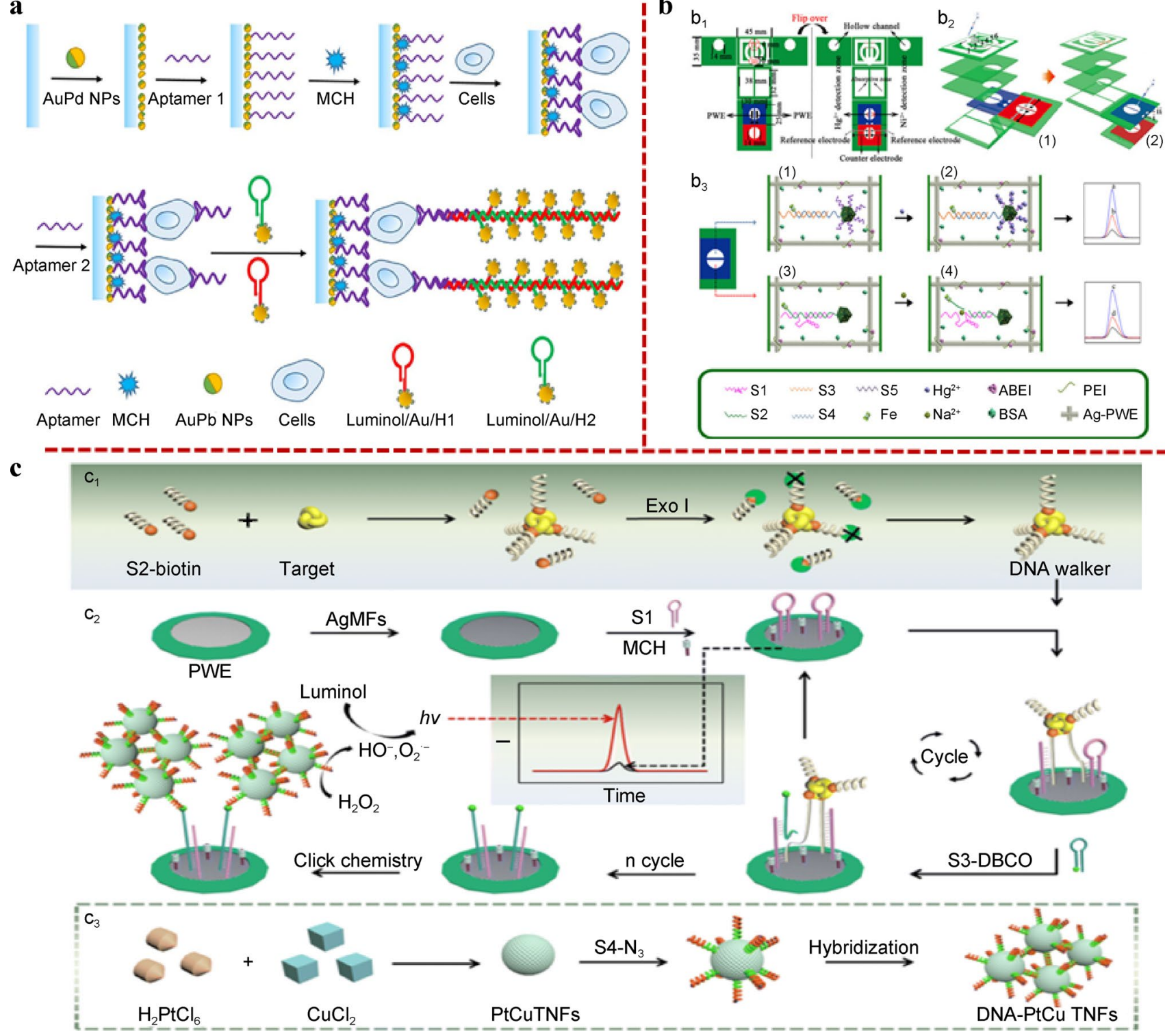

Fig. 2 Some examples for ECL detection. a Paper-based ECL device for MCF-7 detection [84]; b Schematic illustration for paper-based ECL device for $\mathrm{Ni}^{2+}$ and $\mathrm{Hg}^{2+}$ detection [86]; $\mathbf{c}$ Principle for paper-based ECL device of the analyte-triggered DNA walker [88]

interaction between AgTNPs and iodine [138], changed the color from blue to white and the LOD for iodine was $7 \mu \mathrm{g} / \mathrm{L}$.

Besides, colorimetric measurement based on distance is a distinctively visual quantitative method. The colored length on $\mu \mathrm{Pad}$ has the relation to the concentration of targets [139, 140]. For instance, a distance-based method [107] for $\mathrm{Hg}^{2+}$ testing was developed. A precipitated tetramethylbenzidine (TMB) was immobilized on paper chip. When DNAzymes reacted with $\mathrm{Hg}^{2+}$, the G-quadruplexhemin DNAzymes was formed and a color band was generated (Fig. 3a). A trace concentration of $0.23 \mathrm{nmol} / \mathrm{L}$ for $\mathrm{Hg}^{2+}$ was detected.

\subsubsection{Biochemical Analysis}

As for biomedical analysis, a visual colorimetric $\mu$ Pads [115] was developed by the in situ synthesis of a hybrid functional material, GOx@ $\mathrm{Mn}_{3}\left(\mathrm{PO}_{4}\right)_{2}$. The content of glucose in biological samples can be detected with LOD of $0.01 \mathrm{mmol} / \mathrm{L}$ (Fig. 3b). Proteins, like enzymes and antigens, were also detected by $\mu$ PADs. For example, Gong's team [116] developed a microfluidic platform that collected human serum by a pulling-force spinning top (PFST) and paper-based microfluidic enzyme-linked immunosorbent assay (ELISA) for quantity of $\operatorname{IgA} / \operatorname{IgM} /$ $\mathrm{IgG}$ in an instrument-free way. It can easily isolate the 
Table 1 Summary of the corresponding ECL applications on $\mu$ Pads in the fields of the environment, food, biochemistry in past 5 years

\begin{tabular}{|c|c|c|c|c|c|}
\hline Materials & Target molecule & Samples & Advantages & LOD & Refs. \\
\hline $\begin{array}{l}\text { CdTe QDs- } \mathrm{H}_{2}, \mathrm{Au} @ \mathrm{~g}- \\
\mathrm{C}_{3} \mathrm{~N}_{4}, \mathrm{NSs}-\mathrm{DNA} 1 \text { and } \\
\text { carboxylated } \mathrm{Fe}_{3} \mathrm{O}_{4} \\
\text { magnetic nanoparticles }\end{array}$ & $\begin{array}{l}\text { MiRNA-155 and miRNA- } \\
126\end{array}$ & - & $\begin{array}{l}\text { Favorable linear response } \\
\text { and excellent sensitivity }\end{array}$ & $\begin{array}{l}5.7 \mathrm{fmol} / \mathrm{L} \text { and } \\
4.2 \mathrm{fmol} / \mathrm{L}\end{array}$ & [90] \\
\hline DNA (S1)-AuPd NPs & miRNA-155 & - & $\begin{array}{l}\text { Acceptable specificity } \\
\text { and favorable stability }\end{array}$ & $0.67 \mathrm{pmol} / \mathrm{L}$ & [91] \\
\hline $\begin{array}{l}\text { GQDs load surface vil- } \\
\text { lous Au nanocages }\end{array}$ & CA153 & MCF-7 cell & Low-cost and fast & $0.0014 \mathrm{U} / \mathrm{mL}$ & [92] \\
\hline $\begin{array}{l}\text { Au@Pd nanoparticles and } \\
\text { Pt-Ni alloy particles }\end{array}$ & MCF-7 cell & MCF-7 cancer cells & $\begin{array}{l}\text { In-situ screening of } \\
\text { anticancer drugs and } \\
\text { monitoring the number } \\
\text { of apoptotic cancer cells }\end{array}$ & 300 cells $/ \mathrm{mL}$ & [93] \\
\hline $\begin{array}{l}\text { Three separated arrays of } \\
\text { reservoirs }\end{array}$ & HL-60 cancer cells & HL-60 cancer cells & $\begin{array}{l}\text { Distinguish the tumor } \\
\text { cells from normal cells }\end{array}$ & 80 cells $/ \mathrm{mL}$ & [94] \\
\hline A bipolar electrode array & MCF-7 cell & MCF-7 cell & $\begin{array}{l}\text { Simple and suitable for } \\
\text { high-throughput detec- } \\
\text { tion }\end{array}$ & 52 cells $/ \mathrm{mL}$ & [95] \\
\hline $\begin{array}{l}\mathrm{HRP} \text { functionalized } \mathrm{Au} \\
\text { nanocubes }\end{array}$ & $\mathrm{Pb}^{2+}$ & Lake water & $\begin{array}{l}\text { Portable, low-cost and } \\
\text { high efficiency }\end{array}$ & $0.52 \mathrm{nmol} / \mathrm{L}$ & [96] \\
\hline $\begin{array}{l}\mathrm{PFCeO}_{2} \mathrm{NPs} \text { and } 50 \mathrm{~nm} \\
\mathrm{Ag} \mathrm{NPs}\end{array}$ & $\mathrm{Pb}^{2+}$ & Mineral water & $\begin{array}{l}\text { A wide linear range, good } \\
\text { selectivity and repro- } \\
\text { ducibility }\end{array}$ & $0.016 \mathrm{nmol} / \mathrm{L}$ & [97] \\
\hline $\begin{array}{l}\text { Green-luminescent } \\
\text { N-GQDs }\end{array}$ & $\alpha$-fetoprotein & Human serum & $\begin{array}{l}\text { A wide calibration range, } \\
\text { good specificity }\end{array}$ & $1.2 \mathrm{pg} / \mathrm{mL}$ & [98] \\
\hline $\begin{array}{l}\text { Magnet-controlled self- } \\
\text { circulating chip }\end{array}$ & $\begin{array}{l}\text { Circulating tumour } \\
\text { nucleic acids (CTNAs) } \\
\text { in serum clinical CTNA } \\
\text { samples }\end{array}$ & Blood samples & $\begin{array}{l}\text { Highly efficient signal } \\
\text { generation and desirable } \\
\text { specificity }\end{array}$ & $100 \mathrm{amol} / \mathrm{L}$ & [99] \\
\hline $\begin{array}{l}\text { Graphite paper, Pt NPs, } \\
\text { chitosan-multi-walled } \\
\text { carbon nanotubes (CS- } \\
\text { MWCNTs) and Au@Pt } \\
\text { nanostructures }\end{array}$ & $\begin{array}{l}\mathrm{H}_{2} \mathrm{O}_{2} \\
\mathrm{CEA}\end{array}$ & Human serum sample & $\begin{array}{l}\text { High selectivity, a wide } \\
\text { linear range, good } \\
\text { reproducibility }\end{array}$ & $\begin{array}{l}0.5 \mu \mathrm{mol} / \mathrm{L}(\mathrm{S} / \mathrm{N}=3) \text { of } \\
\mathrm{H}_{2} \mathrm{O}_{2} \\
5.0 \mathrm{pg} / \mathrm{mL} \text { for CEA }\end{array}$ & [100] \\
\hline $\begin{array}{l}\text { Silica nanochannel- } \\
\text { assisted electrode }\end{array}$ & Alkaloidal drugs & Buffers and human serum & $\begin{array}{l}\text { Flexibility and univer- } \\
\text { sality }\end{array}$ & $\begin{array}{l}1.799 \mathrm{nmol} / \mathrm{L} \text { and } \\
11.43 \mathrm{~mol} / \mathrm{L}\end{array}$ & [101] \\
\hline Bipolar electrodes & $\begin{array}{l}\text { Glucose, lactate and } \\
\text { cholinc }\end{array}$ & Human serum & $\begin{array}{l}\text { Simple, efficient and } \\
\text { versatile }\end{array}$ & $\begin{array}{l}7.57 \mu \mathrm{mol} / \mathrm{L}, 8.25 \mu \mathrm{mol} / \mathrm{L} \\
\text { and } 43.19 \mu \mathrm{mol} / \mathrm{L}\end{array}$ & [102] \\
\hline Bipolar electrodes & pathogenic DNAs & - & $\begin{array}{l}\text { High sensitivity and mul- } \\
\text { tiplexed analysis }\end{array}$ & $0.1 \mathrm{fmol} / \mathrm{L}$ & [103] \\
\hline
\end{tabular}

serum without any clinical apparatus, and a portable smart phone made it easy to record the intensity signal. Moreover, in 2020, Li's group[117] presented a microfluidic system that can centrifugate human whole blood and quantify carcinoembryonic antigen and alpha fetoprotein by ELISA method with LODs of $360 \mathrm{pg} / \mathrm{mL}$ and $280 \mathrm{pg} / \mathrm{mL}$ for CEA and AFP, respectively. Chandra [120] detected alkaline phosphatase (ALP) using colorimetric method on $\mu$ Pad by antibody immobilization on paper surface. The LOD for the ALP detection was $0.87( \pm 0.07) \mathrm{U} / \mathrm{mL}$. To wash the nonspecific-binding antibody from the paper surface, a novel continuous washing strategy with ring-oven was established by our team [121]. To verify the washing results, HRP-catalyzed 3,3',5,5'-tetramethylbenzidine
(TMB) $-\mathrm{H}_{2} \mathrm{O}_{2}$ colorimetric system was used for CEA detection with the lower LOD of $0.03 \mathrm{ng} / \mathrm{mL}$ (Fig. 3c). Moreover, the detection of nucleic acids can also be carried out on paper with super low LOD. Shu's group [123] has developed a micro-patterned paper device ( $\mu$ PPD)based colorimetric strategy for double-stranded DNA (dsDNA) detection by using polydiacetylene (PDA) vesicles. The quantitative analysis of the target can be down to $10 \mathrm{nmol} / \mathrm{L}$. By using dye-based reaction, Goswami [124] reported a colorimetric method for pan malaria and $\mathrm{P}$. falciparum species detection with LODs of $61.50 \pm 6.43 \mathrm{pmol} / \mathrm{L}$ for $\mathrm{PLDH}$ and $63.97 \pm 7.24 \mathrm{pmol} / \mathrm{L}$ for Pf GDH, respectively. In 2019, Chen's team [125] has developed a rapid and sensitive colorimetric sensing 


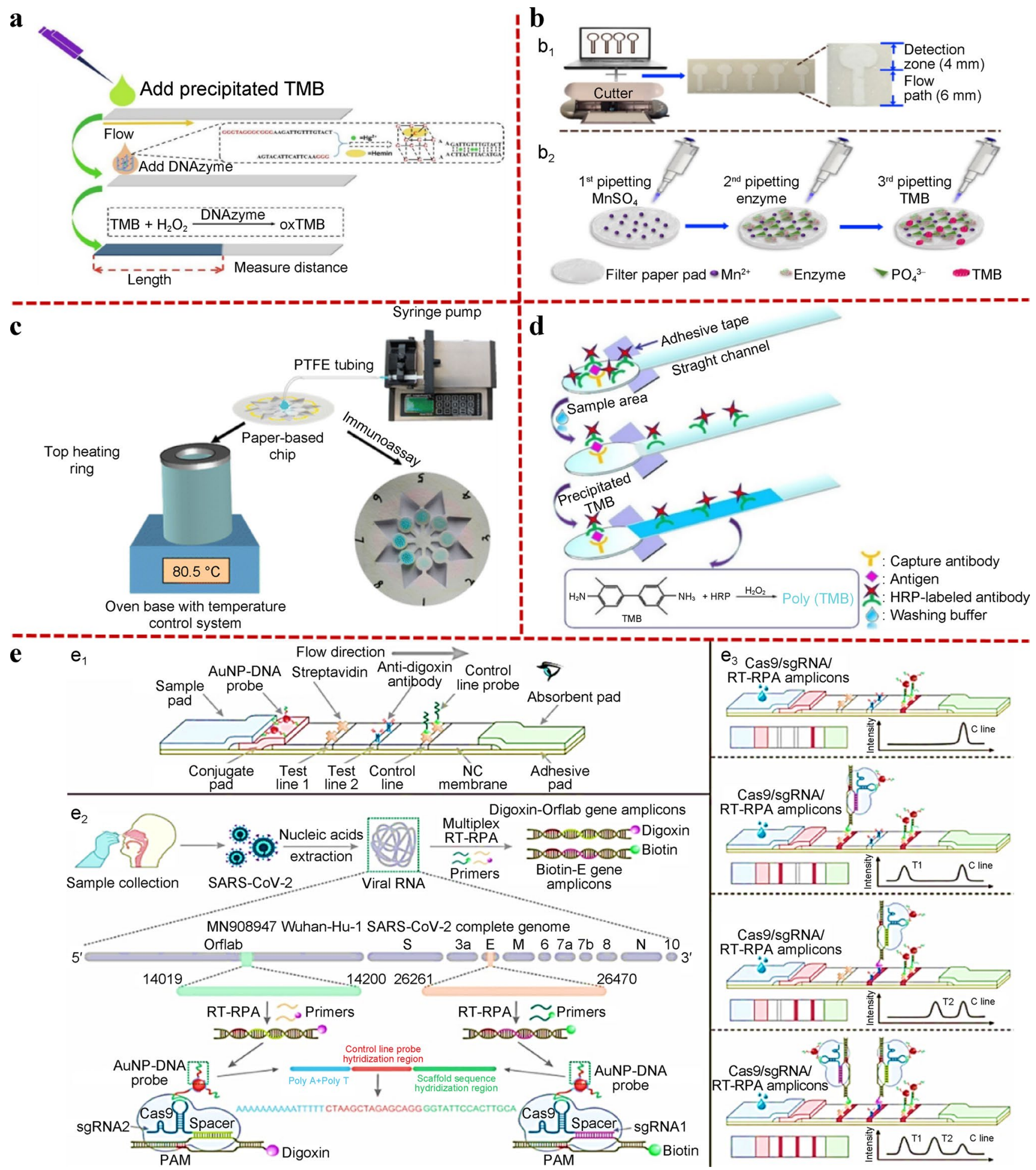

Fig. 3 Some examples for colorimetric detection. a Distance assay for $\mathrm{Hg}^{2+}$ by using G-quadruplex DNAzyme [107]; b Illustration of enzyme-inorganic hybrid nanomaterials synthesized on paper chips
[115]; c Schematic diagram for ring-oven washing procedure [121]; d Illustration of distance detection for CEA biomarker [141]; e Design of the CRISPR/Cas9-mediated TL- lateral flow strip. [127]

Furthermore, a distance-based paper analytical device (dPAD) [126] was fabricated to realize the loop-mediated isothermal amplification (LAMP) and semiquantitative 
determination of genomic DNA in E. coli as low as $4.14 \times 10^{3}$ copies $/ \mu$ L. For immunoassay, CEA was semiqualitative detected by our team with distance-based colorimetry [141]. With the precipitated TMB- $\mathrm{H}_{2} \mathrm{O}_{2}$ added on the paper-based device, LOD of $2 \mathrm{ng} / \mathrm{mL}$ can be obtained with a visible bar (Fig. 3d). In 2021, a non-immunoassay dPAD was introduced for the detection of cardiac troponin I (TnI) [142]. Without any external blood separation, TnI in whole blood samples was determined by using the $\mathrm{dPAD}$ with the LOD of $0.025 \mathrm{ng} / \mathrm{mL}$.

In the field of biochemical analysis, the lateral flow assay (LFA) [143-147] is another common visual platform. Targets usually are induced by lateral capillary force and then react with the biorecognition molecules which are bonded on the porous membrane surface. The results can be read out via colored molecule-labeled biorecognition molecules. LFA is a potential candidate for POCT because of simple operation and one-step analysis procedure. For example, Hou's team [146] has developed a LFA for the simultaneous detection of glucose and glycation ratios in human serum albumin. In 2021, an ultrasensitive LFA [147] was introduced for the determination of the telomerase activity. With the deblocking of ssDNase activity of CRISPR/Cas12a by telomerase extends activators, the telomerase activity was detected as low as 57 cells/mL within $1 \mathrm{~h}$. In 2020, as SARSCoV-2 was spread around the world, LFA [127, 148] was regarded as the most efficient way to realize POCT. A tripleline lateral flow assay (TL-LFA) for the dual-gene detection of SARS-CoV-2 was established [127]. With the CRISPR/ Cas9 mediating, multiplex reverse transcription-recombinase polymerase amplification (RT-RPA) was realized. The genes of envelope (E) and open reading frame lab (Orflab) were detected from the RNA standards in cell-cultured SARS-CoV-2 and SARS-CoV-2 viral. The LOD was 100 RNA copies of $25 \mu \mathrm{L}$ reaction (Fig. 3e). Furthermore, other DNA analysis using LFA were reported [128, 129]. Cui's team has developed a tetra-primer amplification refractory mutation system (ARMS)-polymerase chain reaction (PCR)LFA for the detection of two alleles [125] within $75 \mathrm{~min}$. Jauset-Rubio [129] has reported a LFA for the multi-channel detection of DNA in Francisella tularensis and Yersinia pestis. Using isothermal recombinase polymerase amplification, the assay results were obtained within $1 \mathrm{~h}$ and the LOD was $243 \mathrm{fg}$ for Francisella tularensis and $4 \mathrm{fg}$ for Yersinia pestis, respectively.

\subsubsection{Food Safety Control}

For food safety, colormetry method can measure the content of toxin [149-151] and drugs [152, 153]. A single-linebased LFA (sLFA) strip [150] without the control line was explored for aflatoxin B1 determination. In this assay, an orthogonal emissive upconversion nanoparticle (UCNP) served as a signal substance and calibrator, which had emission at two wavelengths. Zhou's group [152] has developed a LFA with up-converting phosphor method for the determination of morphine and methamphetamine with LOD of $5 \mathrm{ng} / \mathrm{mL}$ for morphine and $10 \mathrm{ng} / \mathrm{mL}$ for methamphetamine.

\subsection{Fluorescence (FL) Detection}

Fluorescence (FL) is the emission after fluorophores or fluorescent dyes excitated by an energy at certain wavelength. For $\mu$ Pads, FL has been a main optical method with high sensitivity and high selectivity [154].

\subsubsection{Environmental Monitoring}

In the field of environmental monitoring, FL was applied on detection of metal ions [155-162], anion [163-165], gas [155], and organic compounds [166-168]. Liu [155] has reported a FL probe on $\mu$ Pads with carbazole for the detection of $\mathrm{Cu}^{2+}$ and gaseous $\mathrm{H}_{2} \mathrm{~S}$. In 2019, a paper-based platform was established [157] using a hand-held UV lamp as an excitation resource. For $\mathrm{Cd}^{2+}$ detection, the FL emission signal can be captured by a mobile phone. Exploiting thin-shell $\mathrm{CuInS}_{2} @ \mathrm{ZnS}$ QDs, $\mathrm{Cd}^{2+}$ was measured even at a trace concentration of $105.86 \mathrm{nmol} / \mathrm{L}$. Moreover, a $\mu$ Pads was demonstrated for $\mathrm{F}^{-}$detection with the fluorescence resonance energy transfer (FRET) method [163]. The linear range for $\mathrm{F}^{-}$was $0.05-0.55 \mathrm{nmol} / \mathrm{L}$, with a LOD of $9.07 \mathrm{pmol} / \mathrm{L}$ (Fig. 4a). In 2020 [166], taking advantage of the blue luminescence of graphene quantum dots (GQDs), oand p-nitrophenols (ONP and PNP, respectively), two kinds of endocrine disruptors were determined selectively and sensitively. The quantitative analysis of ONP and PNP showed linear ranges of $0.30-60.0 \mu \mathrm{g} / \mathrm{mL}$ and $0.20-40.0 \mu \mathrm{g} / \mathrm{mL}$, respectively, with LODs of $0.07 \mu \mathrm{g} / \mathrm{mL}$ for ONP and $0.03 \mu \mathrm{g} / \mathrm{mL}$ for PNP.

\subsubsection{Biochemical Analysis}

As FL molecules can be used as signal probes, FL has many applications in inbiochemical studies. For instance, $\mu$ Pads with different carbon and quantum dots [169] were reported. Tricolor FL probe was established with the addition of different concentrations of $\mathrm{Cu}^{2+}$. For $\mathrm{Cu}^{2+}$, the LOD was $1.3 \mathrm{nmol} / \mathrm{L}$ in human urine (Fig. 4b). Furthermore, a highly ratiometric fluorescent $\mathrm{N}, \mathrm{S}$ co-doped carbon dots (N,S-CDs) probe towards $\mathrm{ClO}^{-}$[170] detection had been applied to paper-based devices. The N,S-CDs probe showed excellent linearity in the range of $0.067-60 \mu \mathrm{mol} / \mathrm{L}$ with a LOD of $9.1 \mathrm{nmol} / \mathrm{L}$.

In addition, $\mu$ Pads have been used for the rapid detection of chemical molecules (e.g. glucose, dipicolinate (PDA) and so on [171-175]. On the basic of an Eu (III)-EDTA 


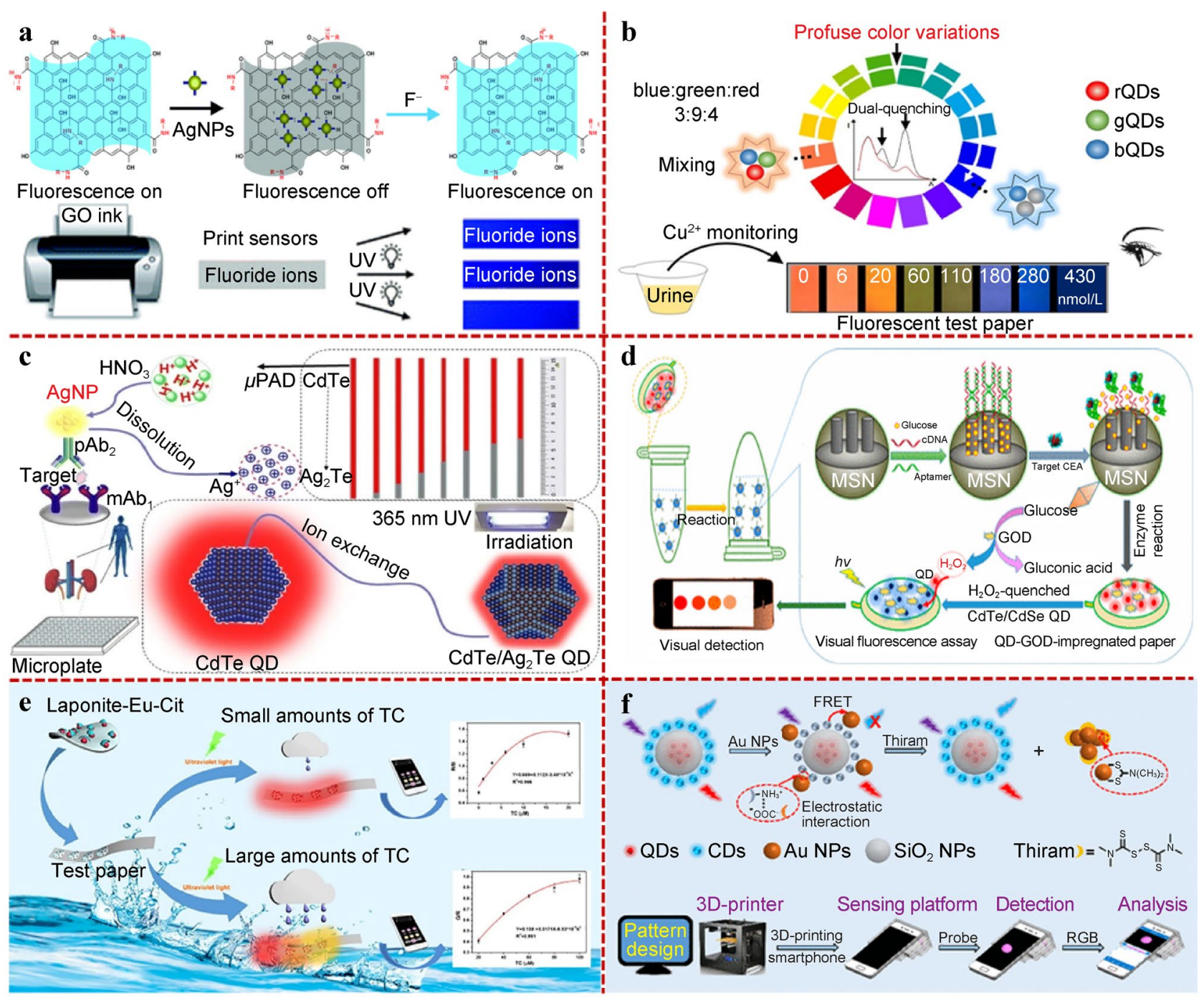

Fig. 4 Some examples for FL detection. a Fluorescence "off-to-on" mechanism on the GO paper for $\mathrm{F}^{-}$detecting [163]; b Schematic illustration of the tricolor probe for $\mathrm{Cu}^{2+}$ [169]; c Illustration of distance-dependent immunoassay on $\mu \mathrm{PAD}$ [177]; d Schematic illustra- tion for FL detection of CEA on $\mu \mathrm{PAD}$ [182]; e Schematic illustration of portable test strips and wearable devices for the analysis of TC [199]; f Schematic illustrations of a single dual-emissive ratiometric probe for thiram by smartphone [203] complexes functionalized poly(diacetylene acid) derived liposomes, a novel ratiometric FL detection system was established on a paper chip for the visual detection of PDA [171]. In 2020, Golmohammadi [175] has reported a cellulose-based wearable patch for sweat biomarker detection. Glucose, lactate, $\mathrm{pH}$, chloride, and volume can all be read out by a smartphone-based FL imaging module. A smartphone APP was also designed in that work.

Besides, $\mu$ Pads have measured various proteins (enzymes and antibodies) in whole blood, urine, saliva and sweat, as they are regarded as biomarkers of some diseases [176-181]. Lin's group has described a paper-based immunoassay for the matrix metalloproteinase-7 (MMP7) detection, which was corresponding to renal cancer [177]. Based on sandwich-type immunoreaction, silver nanoparticles (AgNPs) were first labeled with secondary antibodies. After immunoassay, the signal antibody with silver nanoparticles was dissolved in nitric acid to produce $\mathrm{Ag}^{+}$. CdTe quantum dot was firstly physically adsorped on the nitrocellulose membrane. Due to quenching effect $\mathrm{Ag}^{+}$, the distances can produce on the paper-based chip under $365 \mathrm{~nm}$ shining. With the concentration of MMP7 increased, the quenching distance increased and the LOD was as low as $7.3 \mathrm{pg} / \mathrm{mL}$ (Fig. 4c). Besides, enzyme activity also can be detected by $\mu$ Pads [179-181]. A $\lambda$ exonuclease-assisted paper-based FL assay [179] was described for facile testing of polynucleotide 
kinase (PNK) activity by fluorescence intensity on paper surfaces, achieving sensitivity of PNK activity down to 0.0001 $\mathrm{U} / \mathrm{mL}$. In addition, paper-based FL immunoassays were used commonly for the detection of antibody biomarker [182-185]. CdTe/CdSe QD and relevant enzyme were saturated on paper. Also, DNA-gated mesoporous silica nanocontainers (MSNs) were combined. Then the FL detection of CEA was realized with a low LOD of $6.7 \mathrm{pg} / \mathrm{mL}$ [182] (Fig. 4d).

Furthermore, since nucleic acids are one of the most fundamental biological substances in all organisms [186], the accurate measurement becomes a commom concern for disease diagnosis. Lu [187] has introduced a paper-based sensor system for a nucleic acid amplification test with an internet platform. The paper-based sensor enabled genomic DNA's identification for Escherichia coli and Campylobacter jejuni, with the LOD of $2 \times 10^{3}$ copies $/ \mu \mathrm{L}$. Other $\mu$ Pads for nucleic acid detection [188-192] have been summarized in Table 2. Another important application for $\mu$ Pads is to directly detect cells. In 2020, a fluorescence method was established on a dual-layer paper microfluidic chip for the detection of ROR1 + [193]. A smartphone-based FL microscope and automated image processing were established to enumerate particles, with the LOD of 1 cell $/ \mu \mathrm{L}$.

\subsubsection{Food Safety Control}

Simple, rapid, and instrument-free quantitative detection is very vital for the effective food safety control [194]. Especially, inorganic content [195-197] in water and food is one of the concerns by modern citizens. For example, a $\mu \mathrm{Pad}$ was designed for membraneless gas-separation and iodate determination by using the bovine serum albumin-stabilized gold nanoclusters (BSA-AuNCs) [196]. Based on the fact that gold core of BSA-AuNCs was etched and the red emission was quenched, the iodate was monitored by fluorometric detection with LOD of $0.005 \mathrm{mmol} / \mathrm{L}$. In 2019, a ratiometric fluorescent nanoprobe, label-free carbon dots (CDs), with dual emission at 477 and $651 \mathrm{~nm}$ was used for the selective detection of $\mathrm{Pb}^{2+}$ and pyrophosphate (PPi) with LODs as low as $0.055 \mathrm{mmol} / \mathrm{L}$ and $0.089 \mathrm{mmol} / \mathrm{L}$, respectively [197]. Fu's team [198] has introduced a $\mu \mathrm{Pad}$ integrated with a portable fluorometric system for formaldehyde $\left(\mathrm{CH}_{2} \mathrm{O}\right)$ detection in the linear range of $0.2-2.5 \mathrm{ppm}$.

Fluorescent paper sensors also have been applied for monitoring various chemicals like antibiotics [199-201] and pesticides [202-204]. $\mu$ Pads were designed for the detection of tetracycline (TC), relying on multi-color fluorescence change of a glove-based visual probe [199]. Combined with smartphone-based chromaticity analysis APP, the portable detection of TC was obtained with LOD of $9.5 \mathrm{nmol} / \mathrm{L}$ (Fig. 4e). Jiang's group [203] has reported a dual-emissive ratiometric paper strip consisting of an UV lamp and
3D-printing technology for the smartphone-based analysis of pesticide in a "on-off-on" fluorescent mode with a LOD of $59 \mathrm{nmol} / \mathrm{L}$ (Fig. 4f).

\subsection{Surface-Enhanced Raman Scattering (SERS)}

SERS sensors on paper have been a hot detection method in recent years. When the nanomaterials are modified on the paper surface, SERS can be increased by the nanomaterials. For example, the gold/silver nanoparticles (Au/AgNPs) drop on the paper. Then it will produce precipitation and generate hot spots to increase the sensitivity of detection. SERSbased test samples can be divided into three categories.

\subsubsection{Environmental Applications}

The exploration of content of rhodamine (R6G) in rain water had been operated successfully by constructing a 3D SERS paper strip. R6G can be selectively detected with the minimum magnitude of $1 \times 10^{-11} \mathrm{~mol} / \mathrm{L}$ by using silver mirror reaction [205]. Also, Au/AgNP-based paper sensor was used to explore rhodamine $\mathrm{B}(\mathrm{RhB})$ and crystal violet (CV) in deionized water and tap water [206-208]. Kim's team fabricated the M13 bacteriophage-functionalized silver nanowires (AgNWs) SERS sensor for capturing pesticides, especially paraquat (PQ) [209]. Zhang's group has developed the 3D Silver Dendrites for the determination of Neonicotinoid with the LOD of $0.02811 \mathrm{ng} / \mathrm{mL}$. The platform made great contributions for detecting various contaminants [210]. In 2021, Liu's team prepared an MXene $\left(\mathrm{Ti}_{3} \mathrm{C}_{2} \mathrm{Tx}\right)$ -Ag nanoparticles (NPs) hybrid SERS biosensor for detecting adenine molecules in biological environment with the LOD of $1 \times 10^{-8} \mathrm{~mol} / \mathrm{L}$ [211]. Wang's group used superhydrophobic SERS substrates to detect nitenpyram in the field of agriculture with the LOD of $1 \mathrm{nmol} / \mathrm{L}$ [212]. Some applications in environment [213-216] are shown in Table 3.

\subsubsection{Food Applications}

In Poppi's group, AuNP-based paper substrate was applied in SERS to detect crystal violet sample and to explore the amount of nicotine and uric acid. The respective LODs were $20 \mu \mathrm{g} / \mathrm{L}$ for nicotine and $30 \mu \mathrm{g} / \mathrm{L}$ for uric acid [217]. In order to get a sensitive SERS signal, AgNPs/RGO, AgNF/ AgNP arrays, AgNP and AuNP based paper substrates were also used in the field of food applications [218-221]. Pesticides were detected by paper-based SERS method [222]. Silver nanoparticles and graphene oxide were printed on the paper surface. Thiram, thiabendazole and methyl parathion were measured with low LOD. A two-dimensional $\mathrm{MoO}_{3}-\mathrm{x}$ nanosheet ink was produced in Lan's group to test crystal violet and malachite green on the fish surface by office inkjet printer [223]. Rhodamine $6 \mathrm{G}$ and rhodamine $\mathrm{B}$ can 


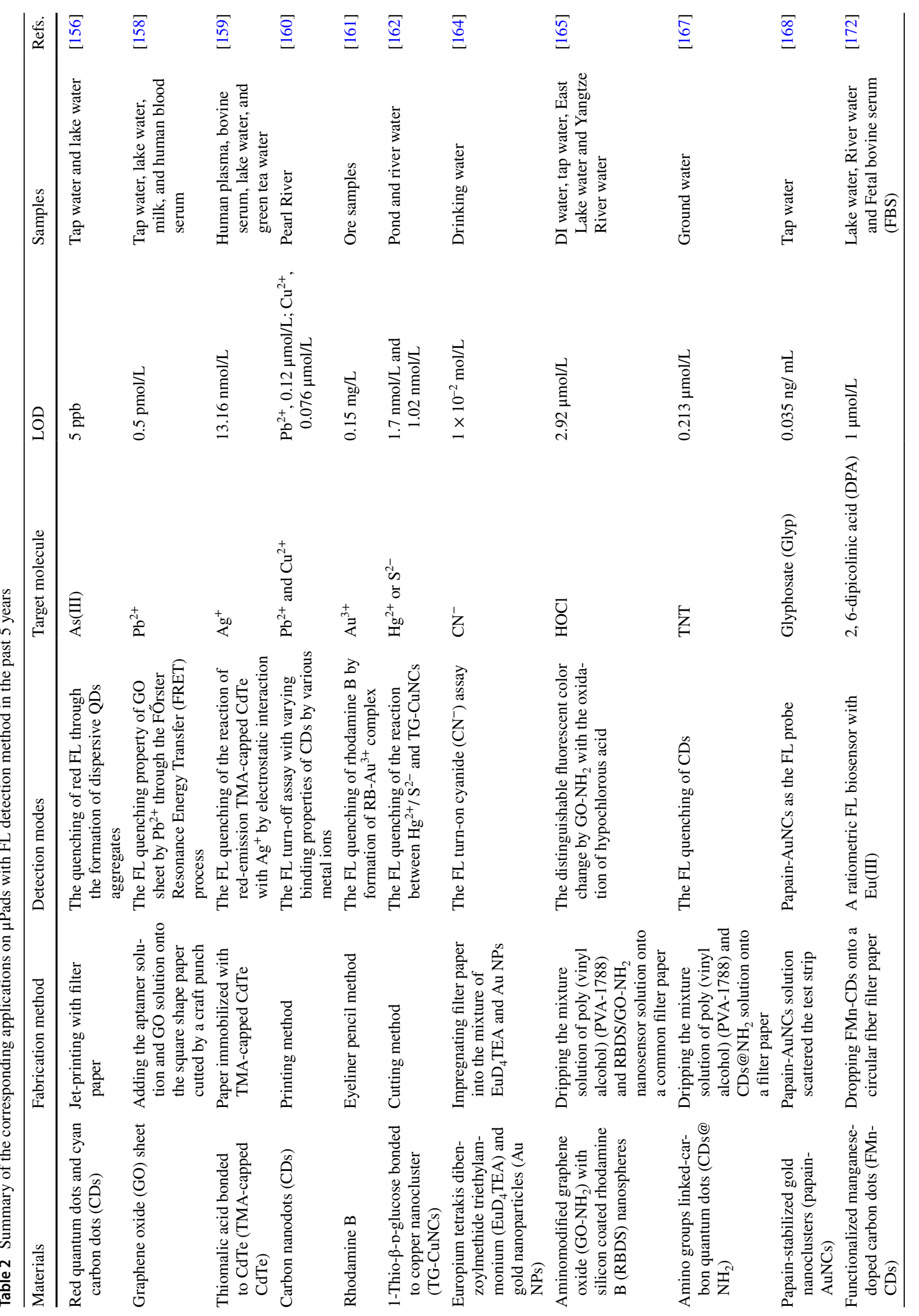




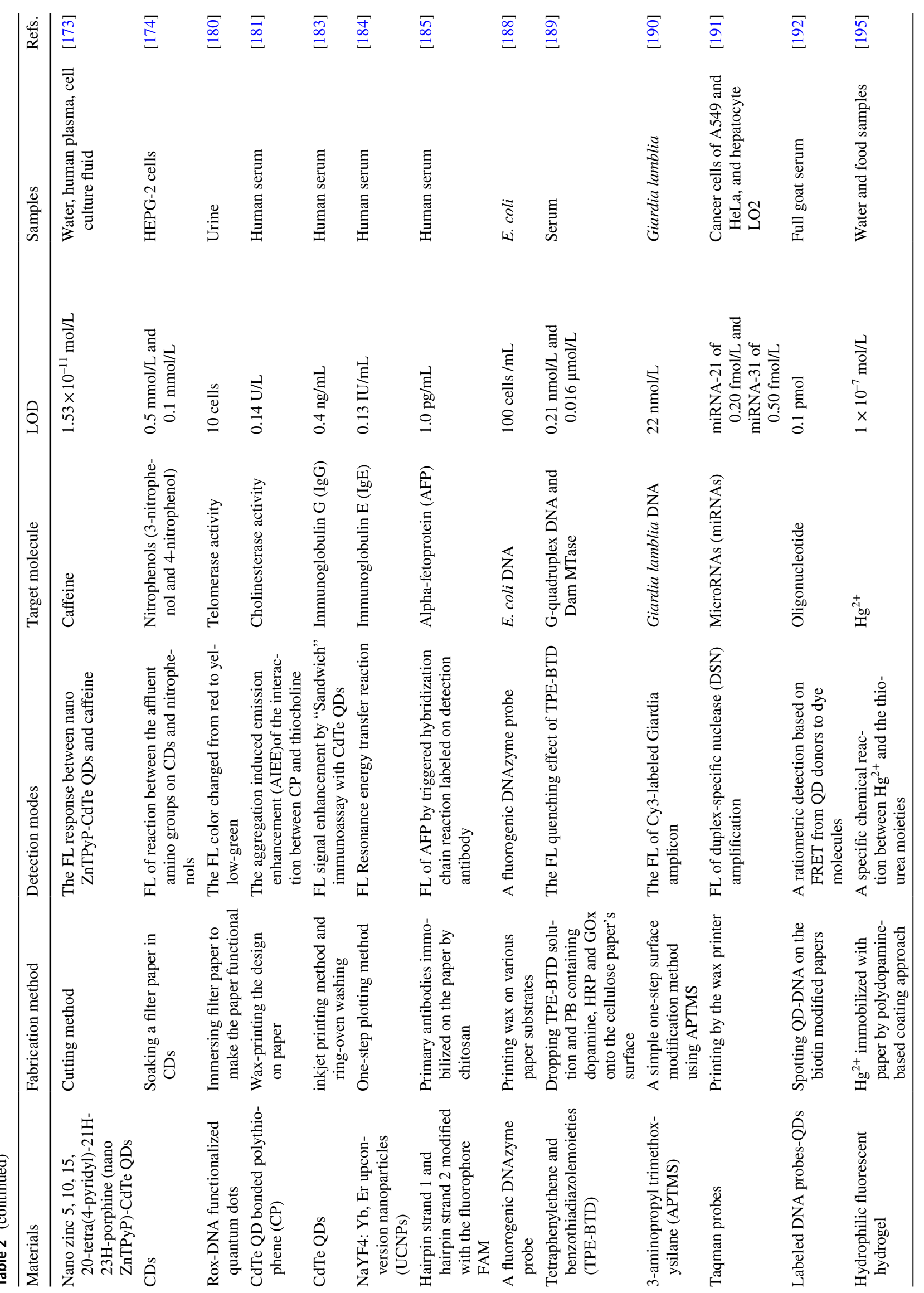




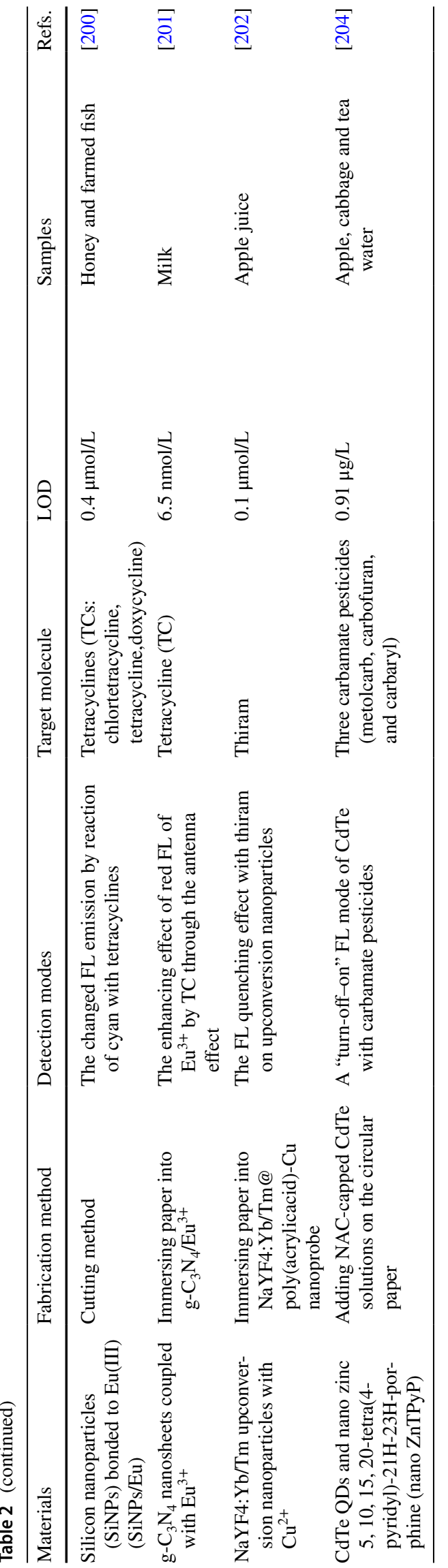

be detected with SERS in vegetables and contaminants in rain, pond, and tap water [224]. A sensitive SERS detection of R6G with a linear range of $1 \times 10^{-9}-1 \times 10^{-5} \mathrm{~mol} / \mathrm{L}$ and a detection limit of $1 \times 10^{-11} \mathrm{~mol} / \mathrm{L}$ was also realized [225]. Xu's team [226] used SERS signal intensity and chiral signal intensity to detect different concentrations of $\mathrm{C}$. jejuni spiked in milk samples with a good linearity from $1 \times 10^{2}$ to $1 \times 10^{6} \mathrm{cfu} / \mathrm{mL}$. Also, Zhang's group has detected melamine in the sample of milk based on paper SERS with a LOD of $1 \mathrm{ppm}$ and a good linear correlation (1-1000 ppm) [227]. Haddad's group provided a simple and sensitive way for analysis of fentanyl in Heroin [228], and Li's group has detected $\mathrm{SO}_{2}$ in wine from $1 \mu \mathrm{mol} / \mathrm{L}$ to $2000 \mathrm{mmol} / \mathrm{L}$ with $\mu$ Pads SERS sensor [229] (Fig. 5a). Besides, it is very important to detect drug concentration. Ameku's group [230] has designed a $\mu$ PAD based SERS to identify caffeine, paracetamol, and levamisole adulterants simultaneously. In our daily life, it is important to detect some dyes' concentration in food safety field. Gu's group presented a novel seed-mediated growth method for making a SERS device. The method can detect Methylene Blue with LOD down to $1 \times 10^{-9} \mathrm{~mol} / \mathrm{L}$. Also, the LOD was $1 \times 10^{-8} \mathrm{~mol} / \mathrm{L}$ for both Crystal Violet and Rhodamine 6G solution [231]. AgNF based paper-SERS [232] and pressure paper spray mass spectrometry (PS-MS) were all used to detect ketoprofen with LODs of 0.023 and $0.076 \mathrm{mg} / \mathrm{L}$ respectively. $\mathrm{SiO}_{2} / \mathrm{Ag}$ nanocomposite-based paper substrate [233] was applied to detect acrylamide (AAm) with SERS (Fig. 5c). Dao's group [234] has developed a new detection method for monitoring the pesticide chlorpyrifos with paper SERS. Lv's group found that $\mathrm{MoS}_{2} @ \mathrm{Au} / \mathrm{Ag}$ hybrid- based paper device exhibited a distinct advantage to separate and preconcentrate in biological and chemical detection [235] (Fig. 5b). Chen's team has fabricated $\mu$ PAD combined with SERS for exploring sulphite in wine, which showed a good linearity from 5 to $300 \mu \mathrm{g} / \mathrm{mL}$ [236]. Huang's group explored a novel label-free 3D-SERS substrate with black phosphorus-Au filter paper, which can detect three types of target bacteria including Staphylococcus aureus, Listeria monocytogenes and Escherichia coli at the same time [237] (Fig. 5d). Paper-based lateral flow immunoassay (LFIA) based on $\left(\mathrm{Fe}_{3} \mathrm{O}_{4} / \mathrm{Au}-\mathrm{PEI}\right)$ nanoparticles tested bacteria in urine and milk samples with a good linearity from $1 \times 10^{1}$ to $1 \times 10^{7} \mathrm{cfu} / \mathrm{mL}$ in less than $60 \mathrm{~min}$ [238]. A paper-based SERS sensor with AgNPs can detect methyl parathion quickly in the sample of fruit [239], tartrazine in Children's snacks [240], crystal violet (CV) and the fungicide thiram in food [241]. Wu's team has separated and identified lycopene and $\beta$-carotene in food products successfully with paper SERS [242]. Cellulose nanofibers (CNF)/AuNP nanocomposite-based paper SERS sensor was used to detect thiram with the LOD of $52 \mathrm{ppb}$ [243]. Also, SERS sensor showed a LOD of $1 \times 10^{-7} \mathrm{~mol} /$ Lfor methylene blue in the 
Table 3 Summary of the corresponding SERS applications on $\mu$ Pad in the fields of the environment, food, biochemistry in 2021

\begin{tabular}{|c|c|c|c|c|c|}
\hline Materials & Operation method & Target molecule & LOD & Samples & Refs. \\
\hline $\begin{array}{l}\text { A mixture of silver nano- } \\
\text { particle (AgNP) and } \\
\text { gold nanostar (AuNS) }\end{array}$ & $\begin{array}{l}\text { Dropping the solution } \\
\text { on cellulose nanofiber } \\
(\mathrm{CNF})\end{array}$ & Ferbam & $50 \mu \mathrm{g} / \mathrm{kg}$ & Kale leaves & [213] \\
\hline Colloidal nanoparticles & $\begin{array}{l}\text { Spraying nanoparticles } \\
\text { onto hydroxyethyl cellu- } \\
\text { lose (HEC) }\end{array}$ & Thiram & $1 \times 10^{-7} \mathrm{~mol} / \mathrm{L}$ & Mud & [214] \\
\hline $\begin{array}{l}\text { Silver nanodots on three- } \\
\text { dimensional cellulose } \\
\text { fibers }\end{array}$ & $\begin{array}{l}\text { A magnetic bead-based } \\
\text { separation method }\end{array}$ & R6G (II), TAMRA & $\begin{array}{l}153.53 \text { and } \\
230.37 \mathrm{pmol} / \mathrm{L} \text { for R6G } \\
\text { and TAMRA }\end{array}$ & Dyes & [215] \\
\hline Au@Ag core-shells & $\begin{array}{l}\text { A electrospun paper } \\
\text { matrix }\end{array}$ & methamphetamine & $7.2 \mathrm{ppt}$ & Wastewater & [216] \\
\hline Silver nanoparticles & $\begin{array}{l}\text { Immersing nanoparticles } \\
\text { in melted wax vessel }\end{array}$ & $\begin{array}{l}\text { 2,4-dichlorophenoxy- } \\
\text { acetic acid }\end{array}$ & $1.0 \times 10^{-4} \mathrm{mg} / \mathrm{g}$ & Green tea & [247] \\
\hline $\begin{array}{l}\text { Au@tannic acid (TNA) } \\
\text { substrate }\end{array}$ & In-situ growth on paper & Reductants & - & & [248] \\
\hline $\begin{array}{l}\text { 4-MBA-functionalized } \\
\text { Au@ZIF-8 SERS paper }\end{array}$ & Plasma reduction method & Putrescine and cadaverine & 76.99 and $115.88 \mathrm{ppb}$ & $\begin{array}{r}\text { Spoiled salmon, chicken, } \\
\text { beef, and pork samples }\end{array}$ & [249] \\
\hline Nanogold particles & $\begin{array}{l}\text { Dropping nanoparticles } \\
\text { on plasma-printed } \\
\text { substrate }\end{array}$ & Cocaine & $1 \mathrm{ng} / \mathrm{mL}$ & Cocaine & {$[250]$} \\
\hline $\begin{array}{l}\text { Uniform gold nano- } \\
\text { spheres treated by } \\
\text { chloride ion }\end{array}$ & $\begin{array}{l}\text { Self-assembling nanopar- } \\
\text { ticles on paper }\end{array}$ & Fentanyl citrate & $\begin{array}{c}0.59 \mu \mathrm{g} / \mathrm{mL} \text { and } \\
2.78 \mu \mathrm{g} / \mathrm{mL}\end{array}$ & Urine and serum & {$[268]$} \\
\hline Gold nano-pyramid arrays & $\begin{array}{l}\text { Dropping nanoparticles } \\
\text { on paper }\end{array}$ & S-100 $\beta$ & $5.0 \mathrm{pg} / \mathrm{mL}$ & Blood plasma & [269] \\
\hline $\begin{array}{l}\text { Goldnanostar@Raman } \\
\text { reporter@ silicasand- } \\
\text { wiched nanoparticles }\end{array}$ & $\begin{array}{l}\text { Dropping nanoparticles } \\
\text { on paper }\end{array}$ & $\begin{array}{l}\text { Carcinoembryonic } \\
\text { antigen }\end{array}$ & $1.0 \mathrm{ng} / \mathrm{mL}$ & Whole blood & {$[270]$} \\
\hline $\begin{array}{l}\text { Gold nanoparticles (Au } \\
\text { NPs) }\end{array}$ & Dropping nanoparticles & Serum & $10 \mathrm{ppm}$ & Blood & {$[271]$} \\
\hline Silver-nanowires & $\begin{array}{l}\text { Dropping nanoparticles } \\
\text { on paper }\end{array}$ & DNA & $3.12 \mathrm{pg} / \mu \mathrm{L}$ & $\begin{array}{l}\text { Various bacteria and } \\
\text { viruses }\end{array}$ & {$[272]$} \\
\hline
\end{tabular}

sample of apples [244]. Ag@ $\mathrm{SiO}_{2}$ core-shell nanoparticles [245] were used on filter paper to fabricate SERS chips. The chips were used for detecting the amount of thiram with the LOD of $1 \times 10^{-9} \mathrm{~mol} / \mathrm{L}$, which had great potential in pesticide residues' detection. Yang's group has explored SERS chips with $\mathrm{Ag} / \mathrm{Au} \mathrm{NPs}$ to detect malachite green, methylene blue and crystal violet with LODs of $4.3 \times 10^{-9}, 2.0 \times 10^{-8}$, and $8.1 \times 10^{-8} \mathrm{~mol} / \mathrm{L}$, respectively. [246]. Other applications in food [247-250] are shown in Table 3.

\subsubsection{Biological Applications}

SERS based paper has also been used in the biological applications. Paper substrate and its biosensing application such as picomolar SERS based paper was used to detect folic acid in picomolar scope for healthcare [251]. SERS paper-based lateral flow strip (PLFS) was good for assisting screening of traumatic brain injury (TBI) patients in a short time. It was used to detect neuron-specific enolase (NSE) with a LOD of $0.86 \mathrm{ng} / \mathrm{mL}$ [252] (Fig. 5e). Qi's group has reported that by using DNA-encoded Raman-active anisotropic nanoparticles on paper, microRNA can be sensitively detected within 15 min with the LOD of $1 \mathrm{pmol} / \mathrm{L}$ [253]. SERS can also be used for distinguishing Zika and dengue nonstructural protein 1(NS1) biomarkers with a high sensitivity [254]. Lorenzo Russo has adopted paper-based immunoassays by SERS with AuAg nanoshells for detecting the biomarker of resistance protein A (MxA) [255]. What's more, a dipstick immunoassay was realized by using AuAg NSs conjugated antibody as a "nanotag". For biomarker detection, SERSbased $\mu$ PAD can be used for quantitative detection of multiple cardiac biomarkers simultaneously. Glycogen phosphorylase isoenzyme BB (GPBB), Troponin T (cTnT) and CK-MB for early diagnosis have been explored simultaneously [256]. SERS containing graphene-isolated-Au-nanocrystals was used to detect bilirubin [257]. Different sampling methods have also been realized in SERS. For example, Merve Ery1lmaz has explored SERS-based lateral flow immunoassay (LFIA) test strips for Group A Streptococcus pyogenes (GAS) detection. By using of the swab sampling technique, 


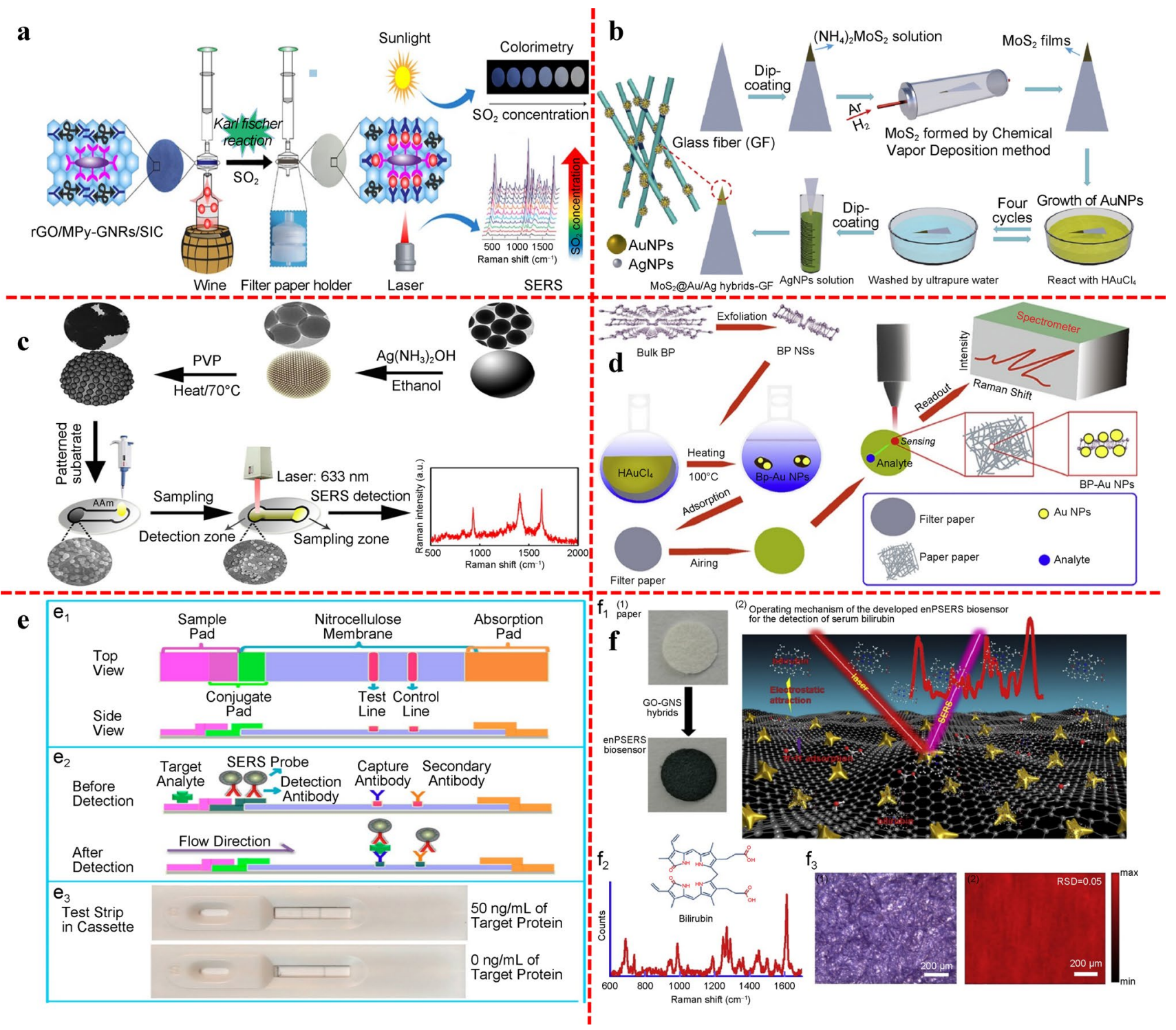

Fig. 5 Some examples for SERS detection. a Schematic illustration of dual-modal detection of $\mathrm{SO}_{2}$ [229]; b Schematic illustration of fabrication of $\mathrm{MoS}_{2} @ \mathrm{Au} / \mathrm{Ag}$ hybrid substrate for SERS [235]; c Schematic illustration of F-SANC substrate fabrication in SERS detection

SERS-based rapid assay got the LOD of $0.2 \mathrm{CFU} / \mathrm{mL}$ for GAS [258]. Also, nanopaper-based analytical devices (nanoPads) were appeared for a new platform. The devices were the natural hydrophilicity and hollow-channel. Pump-free can be realized on the nanopaper. SERS can be performed on this new platform for environmental pollutants detection [259]. A gold-coated magnetic nanoparticle with anti Microcystin-LR (MC-LR) antibody Fab fragments was produced. The relavent antigen can be recognized from aqueous media and blood plasma [260]. In clinical analysis field, diseaserelated substances are important and SERS has successfully realized the disease detection. A paper-based SERS assay was used to explore atherosclerosisa [261]. A nanoporous of AAm [233]; d Schematic illustration of BP-Au filter paper-based SERS substrates for food analysis [237]; e Schematic illustration of SERS paper-based lateral flow strip (PLFS) [252]; f Schematic illustrations of paper-based SERS for serum bilirubin detection [266]

networking membrane was adopted as the substrate and SERS nanotags was used as the signal reading probe. And the LOD was $0.1 \mathrm{pg} / \mathrm{mL}$. Magnetic separation was realized by plasmonic paper-based SERS and the capture accuracy of the HT-29 cells was $83.7 \%$ [262]. Lu has reported the simultaneous detection of two biomarkers of squamous cell carcinoma antigen (SCCA) and osteopontin (OPN) by paperbased SERS method. Au-Ag nanoshuttles (Au-AgNSs) was used as SERS tags. Au nanoflowers (AuNFs) were used to develop a sandwich structure for later immunoassay. The LODs for SCCA and OPN in human serum were $8.628 \mathrm{pg} /$ $\mathrm{mL}$ and $4.388 \mathrm{pg} / \mathrm{mL}$, respectively [263]. Zavyalova's group developed a paper-based device for detection of viruses with 
SERS. SARS-CoV-2 virus can be measured rapidly with better selevtivity [264]. In 2017, a plasmonic filter was used by Wang's group to filtrate, capture and identify Streptomycete spores with SERS method. The device can discriminate the source of nosiheptide product. With this filter, a stain- and PCR-free detection was realized with only $5 \mu \mathrm{L}$ sample solution and $5 \mathrm{~min}$ for the detection time [265]. As reported by Pan [266], a paper-based SERS biosensor was established for free bilirubin detection by label free method. Enrichment function was coupled on this sensor and multifunctional graphene oxide-plasmonic gold nanostar (GO-GNS) hybrids was adopted (Fig. 5f). Adenosine can be used for cancer biomarker. A SERS-chemometric method was established for the detection of urinary adenosine [267]. Some applications in biological [268-272] in 2021 were shown in Table 2.

\subsection{Chemiluminescence (CL)}

To perform sensitively and rapidly in POCT, paper-based platforms in CL system arises great concern.
A novel paper-based CL system with $\mathrm{H}_{2} \mathrm{O}_{2}$-rhodamine $\mathrm{b}$ (RhoB) and MOF was established. MOF used $\mathrm{Co}^{2+}$ as the central ion. The CL system was used for total phenolic content detection. The LODs for gallic acid, quercetin, catechin, kaempferol and caffeic acid were $0.98,1.36,1.48,1.81$ and $2.55 \mathrm{ng} / \mathrm{mL}$, respectively [273] (Fig. 6a). Yahyai reported that polyphosphate (PP) can enhance the CL of graphene quantum dots (GQDs)- $\mathrm{KMnO}_{4}$ system. Deltamethrin (DM) can quench this system's CL. The mechanism was discussed and the CL luminous body was $\mathrm{Mn}^{2+}$. DM can be detected in food samples with the LOD of $0.15 \mu \mathrm{g} / \mathrm{mL}$ [274]. Montali et al. [275] presented a CL foldable paper-based biosensor based on three coupled enzymatic reactions catalyzed by enzyme acetylcholinesterase (AChE), choline oxidase and horseradish peroxidase. The enzyme can catalyze the decomposition of hydrogen peroxide and then organophosphorus (OP) can be detected with its inhibiting effect of AChE. In Yang's work, $\mathrm{Co}^{2+} / \mathrm{N}$-(aminobutyl)-N-(ethylisoluminol) (ABEI) functionalized magnetic carbon composite $\left(\mathrm{Co}^{2+}-\mathrm{ABEI}-\mathrm{Fe}_{3} \mathrm{O}_{4} @\right.$ void@C) was used on a three-dimensional microfluidic paper-based device $(3 \mathrm{D} \mu \mathrm{PAD})$ to detect
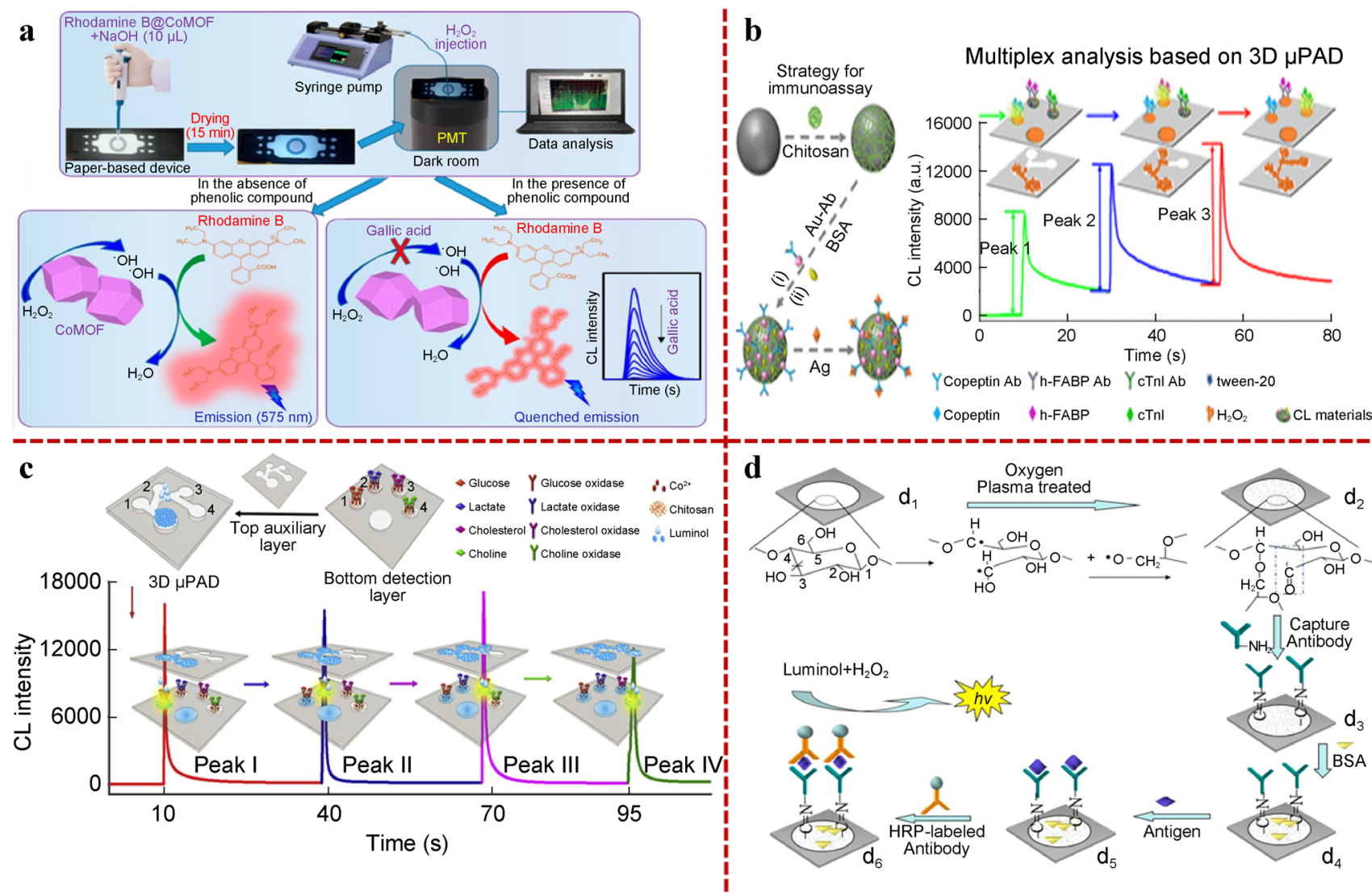

Fig. 6 Some examples for CL detection. a Schematic illustration of $\mu \mathrm{PAD}$ for phenolic compounds detection [273]; b Schematic illustration of 3D $\mu \mathrm{PAD}$ for copeptin, h-FABP and cTnI detection [276]; c Illustration for multiplexed CL analysis on 3D $\mu$ PAD. [277]; d Schematic illustration for the mechanism of plasma treatment of paper for antibody immobilization [15] 
early acute myocardial infarction (AMI) biomarkers in human serum samples. The time-resolved CL signals were used for the simultaneous determination of AMI biomarkers [276] (Fig. 6b). As reported by Li, temporal resolution CL method can be performed with double-layered 3D $\mu \mathrm{PAD}$. Then glucose, lactate, cholesterol and choline can be detected at the same time. $\mathrm{H}_{2} \mathrm{O}_{2}$ was produced after the reaction of enzyme and substrate. The luminol- $\mathrm{H}_{2} \mathrm{O}_{2} \mathrm{CL}$ system was still catalyzed by the cobalt ion. With temporal resolution CL method, the LOD for glucose, lactate, cholesterol and choline was 8, 15, 6 and $0.07 \mu \mathrm{mol} / \mathrm{L}$, respectively [277] (Fig. 6c). In the future, paper-based CL immunodevice by controlling reagent transport can provide a new way of sensitive detection of multi-biomarkers in a short time. For bioanalysis, in Han's work, combined with enzyme-catalyzed CL method, the testing of cardiac troponin I (cTnI) in human serum samples with LOD of $0.84 \mathrm{pg} / \mathrm{mL}$ was achieved [278].

In recent years, our lab has worked on paper-based CL sensing platforms. The paper-based chip was used in biomedical and environmental fields. For instance, a waxprinted CL $\mu \mathrm{Pad}$ for the ofloxacin detection was shown, combined with the luminol- $\mathrm{H}_{2} \mathrm{O}_{2}$-OFLX system enhanced by AgNPs was developed. The LOD for OFLX was $3.0 \times 10^{-10} \mathrm{~g} / \mathrm{mL}$ [279]. A molecularly imprinted polymer (MIP) was successfully synthesized on the paper surface for the CL detection of dichlorvos (DDV). The LOD for DDV detection was $0.8 \mathrm{ng} / \mathrm{mL}$ [280]. A paper-based CL immunodevice prepared by a low-cost antibody immobilization method based on plasma treatment was introduced. The detection of CEA in human serum was performed with a linear range from 0.1 to $80.0 \mathrm{ng} / \mathrm{mL}$ [15] (Fig. 6d). In 2017, a paper-based CL immunodevice by using controlling reagent flowing technique was explored. The technique can change the migration rate for the reagent and then the timedissolved CL detection can be realized on the paper-base device. CEA, carcinoma antigen 125 (CA125) and carbohydrate antigen 199 (CA199) can be detected simultaneously on the paper-based chip with LODs of $0.03 \mathrm{ng} / \mathrm{mL}$, $0.2 \mathrm{U} / \mathrm{mL}$ and $0.2 \mathrm{U} / \mathrm{mL}$, respectively [281]. In 2018, carbon nanospheres with HRP functionalization were used as signal antibody markers to construct a paper-based CL immunodevice for the determination of CEA with the LOD of $3 \mathrm{pg} / \mathrm{mL}$. The method was nearly 10 times more sensitive than commercial Ab2-HRP kits [282]. In 2019, a 3D washing strategy was developed on a paper-based immunodevice using a ring-oven. The 3D washing strategy had a lower background than the flat washing mode, because non-specific binding proteins could be continuously transported to the waste zone by gravity and capillarity. A low LOD of $2 \mathrm{pg} / \mathrm{mL}$ was obtained for the detection of CEA by CL [283]. In 2019, a new fabrication method was used to manufacture a $\mu \mathrm{Pad}$. The recycled polystyrene in chloroform was used as a hydrophobic reagent. A tape mask was adopted to protect the hydrophilic channel. Three cancer biomarkers, CEA, $\alpha$-fetal protein (AFP), prostate-specific antigen (PSA) in human serum samples on the $\mu \mathrm{PAD}$ were detected by luminol- $\mathrm{H}_{2} \mathrm{O}_{2}$ p-iodiophenol (PIP) CL system. The linear ranges were $0.05-80.0 \mathrm{ng} / \mathrm{mL}, 5.0-80.0 \mathrm{ng} / \mathrm{mL}$, $1.0-50.0 \mathrm{ng} / \mathrm{mL}$, respectively [284]. PSA was detected sensitively on a $\mu$ PAD [285] by using $\mathrm{NH}_{2}-\mathrm{MIL}-53(\mathrm{Fe})$ as the detection antibody label. The dual mode detection (FL and CL) was achieved with the LODs of $0.3 \mathrm{ng} / \mathrm{mL}$ for CL and $0.2 \mathrm{ng} / \mathrm{mL}$ for FL. In 2021, it was reported that by using Co-Fe Prussian blue analogue nanocubes (Co-Fe PBA NCs), the strong $\mathrm{CL}$ still happened in the absence of $\mathrm{H}_{2} \mathrm{O}_{2}$ on a paper-based CL device [286].

\section{Conclusion and Outlook}

$\mu$ Pads have been widely used for inorganic ions, organic compounds, proteins, nucleic acid and drug analysis due to the advantages of low-cost, easy-to-fabrication, strongcapilary action and biological compatibility. From the perspective of material synthesis substrate, by in-situ growth on paper chip or in-situ dropping on paper, it can realize detection more sensitively and faster. From the perspective of paper chip design, different injection areas or reaction areas are designed on the surface of the paper base to build a paper-based platform with diversified functions, which can satisfy the requirement of rapid detection of single component or multi-component samples. At present, the commonly used paper-based detection methods are mainly EC, ECL, colorimetry, FL, SERS and CL.

EC method is attractive alternative detection technique for $\mu$ Pads because of its portable size, small instrumentation and high sensitivity. However, the stability of detection electrodes, which corresponds to temperature, $\mathrm{pH}$ and the fabrication cost, still remain a challenge.

Due to the high sensitivity and signal-to-noise ratio of ECL analysis, low detection limits have been achieved for miRNA, tumor cell MCF-7, heavy metal ions, antigens and streptavidin since 2015. The development of equipments is limited, which requires the continuous efforts of scientists. Colorimetric methods have become the most frequently used ones in $\mu$ Pads because the signal readout method is simple. Distance-based and lateral flow assay paper analytical devices are well-established platform because of easy integration with POCT devices. FL detection is a highly sensitive and selective optical analysis technology that can be used for different fields. Paper-based SERS sensors have the advantages of low cost and simple sample collection, but the hydrophilic surface inhibits its sensitivity. This can be improved by modifying nanomaterials on the surface. Then paper-based SERS sensors can be used for the analysis of environmental samples, food samples and biological 
samples. CL analysis is sensitive and fast. The paper-based CL immunoassay devices have the characteristics of controlled reagent delivery, which provide strategies for detecting various antigens and biomarkers of early cancer.

Although paper-based platform has been widely used in various fields, sample pretreatment is still needed in most cases. It still needs a lot of efforts to build paper-based platform to test actual samples directly. In addition, another challenge is that the paper-based devices are not connected to the common products in our daily life, so it is exciting to realize simpler and faster detection mode and build a lifeexperiment integrated platform. Finally, the construction of paper laboratory is also a promising platform. We are looking forward for more designs to indeed realize the micro total analysis on $\mu$ Pads. In addition, POCT has the outlook for home-stay diagnosis on the paper chip; we always believe that more and more people will build multi-dimensional platforms through paper for home-stay diagnosis. Through our joint efforts, paper-based platforms will play an infinite possibility in the future.

Acknowledgements We are grateful to Shaanxi Province Science Foundation (2021JM-193) for funding this work. The authors also thank the Fundamental Research Funds for the Central Universities (GK201902009, GK201701002) and Program for Innovative Research Team in Shaanxi Province (2014KCT-28) for supporting this work.

\section{Declarations}

Conflict of Interest The authors declare that they have no confict of interests.

\section{References}

1. Luppa PB, Müller C, Schlichtiger A, Schlebusch H. Point-ofcare testing (POCT): current techniques and future perspectives. Trends Anal Chem. 2011;30:887-98.

2. Tang RH, Liu LN, Zhang SF, He XC, Li XJ, Xu F, Ni YH, Li F. A review on advances in methods for modification of paper supports for use in point-of-care testing. Microchim Acta. 2019;186:521.

3. Shrivastava S, Trung TQ, Lee N-E. Recent progress, challenges, and prospects of fully integrated mobile and wearable point-of-care testing systems for self-testing. Chem Soc Rev. 2020;49:1812-66.

4. Martinez AW, Phillips ST, Butte MJ, Whitesides GM. Patterned paper as a platform for inexpensive, low-volume, portable bioassays. Angew Chem Int Ed. 2007;46:1318-20.

5. Joung H-A, Ballard ZS, Ma A, Tseng DK, Teshome H, Burakowskie S, Garner OB, Carlo DD, Ozcan A. Paper-based multiplexed vertical flow assay for point-of-care testing. Lab Chip. 2019;19:1027-34.

6. Li C, Boban M, Tuteja A. Open-channel, water-in-oil emulsification in paper-based microfluidic devices. Lab Chip. 2017; 17:1436-41.

7. Ouyang LF, Liu Q, Liang H. Combining field-amplified sample stacking with moving reaction boundary electrophoresis on a paper chip for the preconcentration and separation of metal ions. Sep J Sci. 2017;40:789-97.

8. Jung W, Han J, Choi J-W, Ahn CH. Point-of-care testing (POCT) diagnostic systems using microfluidic lab-on-a-chip technologies. Microelectron Eng. 2015;132:46-57.

9. Fukana N, Sonsa-ard T, Chantipmanee N, Hauser PC, Wilairat $\mathrm{P}$, Nacapricha D. Contactless conductivity sensor as detector for microfluidic paper-based analytical device with application to unique rapid method for quantifying sulfite preservative. Sens Actuators B Chem. 2021;339:129838.

10. Yu L, Shi ZZ. Microfluidic paper-based analytical devices fabricated by low-cost photolithography and embossing of parafilm. Lab Chip. 2015;15:1642-5.

11. Asano H, Shiraishi Y. Development of paper-based microfluidic analytical device for iron assay using photomask printed with 3D printer for fabrication of hydrophilic and hydrophobic zones on paper by photolithography. Anal Chem Acta. 2015;883:55-60.

12. Li YQ, Wang Y, Chen SQ, Wang ZM, Feng L. Inkjet-printed paper-based sensor array for highly accurate $\mathrm{pH}$ sensing. Anal Chem Acta. 2021;1154:338275.

13. Carrilho E, Martinez AW, Whitesides GM. Understanding wax printing: a simple micropatterning process for paper-based microfluidics. Anal Chem. 2009;81:7091-5.

14. Ghosh R, Gopalakrishnan S, Savitha R, Renganathan T, Pushpavanam $\mathrm{S}$. Fabrication of laser printed microfluidic paper-based analytical devices (LP- $\mu$ PADs) for point-of-care applications. Sci Rep. 2019;9:7896.

15. Zhao M, Li HF, Liu W, Guo YM, Chu WR. Plasma treatment of paper for protein immobilization on paper-based chemiluminescence immunodevice. Biosens Bioelectron. 2016;79:581-8.

16. Wang JH, Zhang LS, Li XC, Zhang XL, Yu HZ. From kirigami to three-dimensional paper-based micro-analytical device: cutand-paste fabrication and mobile app quantitation. RSC Adv. 2019;9:23267-75.

17. Nie J, Zhang Y, Lin L, Zhou C, Li S, Zhang L, Li J. Low-cost fabrication of paper-based microfluidic devices by one-step plotting. Anal Chem. 2012;84:6331-5.

18. Olkkonen J, Lehtinen K, Erho T. Flexographically printed fluidic structures in paper. Anal Chem. 2010;82:10246-50.

19. He Y, Wu WB, Fu JZ. Rapid fabrication of paper-based microfluidic analytical devices with desktop stereolithography $3 \mathrm{D}$ printer. RSC Adv. 2015;5:2694-701.

20. Gan W, Gu Y, Han J, Li CX, Sun J, Liu P. Chitosan-modified filter paper for nucleic acid extraction and"in situ PCR"on a thermoplastic microchip. Anal Chem. 2017;89:3568-75.

21. Tang RH, Yang H, Gong Y, You ML, Liu Z, Choi JR, Wen T, Qu ZG, Mei QB, Xu F. A fully disposable and integrated paperbased device for nucleic acid extraction, amplification and detection. Lab Chip. 2017;17:1270-9.

22. Lu W, Zhang JW, Huang YJ. Self-diffusion driven ultrafast detection of ppm-level nitroaromatic pollutants in aqueous media using a hydrophilic fluorescent paper sensor. ACS Appl Mater Interfaces. 2017;9:23884-93.

23. Akyazi T, Basabe-Desmonts L, Benito-Lopez F. Review on microfluidic paper-based analytical devices towards commercialisation. Anal Chem Acta. 2018;1001:1-17.

24. Modha S, Shen Y, Chamouni H, Mulchandani A, Tsutsui H. Laser-etched grooves for rapid fluid delivery for a paper-based chemiresistive biosensor. Biosens Bioelectron. 2021;180:113090.

25. Krikstolaityte V, Ding RY, Xia ECH, Lisak G. Paper as sampling substrates and all-integrating platforms in potentiometric ion determination. Trends Anal Chem. 2020;133:116070.

26. Yang JC, Wang K, Xu H, Yan WQ, Jin QH, Cui DX. Detection platforms for point-of-care testing based on colorimetric, luminescent and magnetic assays: a review. Talanta. 2019;202:96-110. 
27. Gai HW, Li YJ, Yeung ES. Optical detection systems on microfluidic chips. Top Curr Chem. 2011;304:171-201.

28. Matos Pires NM, Dong T, Hanke U, Hoivik N. Recent developments in optical detection technologies in lab-on-a-chip devices for biosensing applications. Sensors. 2014;14:15458-79.

29. Dungchai W, Chailapakul O, Henry CS. Electrochemical detection for paper-based microfluidics. Anal Chem. 2009;81:5821-6.

30. Pinheiro T, Marques AC, Carvalho P, Martins R, Fortunato E. Paper microfluidics and tailored gold nanoparticles for nonenzymatic, colorimetric multiplex biomarker detection. ACS Appl Mater Interfaces. 2021;13:3576-90.

31. Trang TNQ, Vinh LQ, Doanh TT, Thu VTH, Alloy J. Structureadjustable colloidal silver nanoparticles on polymers grafted cellulose paper-based highly sensitive and selective SERS sensing platform with analyte enrichment function. Compd. 2021;867:159158.

32. Guo XY, Zong LJ, Jiao YC, Han YF, Zhang XP, Xu J, Li L, Zhang C-W, Liu ZP, Ju Q, Liu JH, Xu ZH, Yu H-D, Huang W. Signal-enhanced detection of multiplexed cardiac biomarkers by a paper-based fluorogenic immunodevice integrated with zinc oxide nanowires. Anal Chem. 2019;91:9300-7.

33. Sun JL, Li L, Ge SG, Zhao PN, Zhu PH, Wang ML, Yu JH. Dual-mode aptasensor assembled by a $\mathrm{WO}_{3} / \mathrm{Fe}_{2} \mathrm{O}_{3}$ heterojunction for paper-based colorimetric prediction/photoelectrochemical multicomponent analysis. ACS Appl Mater Interfaces. 2021;13:3645-52.

34. Prasad KS, Cao XY, Gao N, Jin QJ, Sanjay ST, Henao-Pabon G, Li XJ. A low-cost nanomaterial-based electrochemical immunosensor on paper for high-sensitivity early detection of pancreatic cancer. Sens Actuators B Chem. 2020;305:127516.

35. Wu YF, Xue P, Kang YJ, Hui KM. Paper-based microfluidic electrochemical immunodevice integrated with nanobioprobes onto graphene film for ultrasensitive multiplexed detection of cancer biomarkers. Anal Chem. 2013;85:8661-8.

36. Morales-Narváez E, Naghdi T, Zor E, Merkoçi A. Photoluminescent lateral-flow immunoassay revealed by graphene oxide: highly sensitive paper-based pathogen detection. Anal Chem. 2015;87:8573-7.

37. Liu QL, Lin Y, Xiong J, Wu L, Hou XD, Xu KL, Zheng CB. Disposable paper-based analytical device for visual speciation analysis of $\mathrm{Ag}(\mathrm{I})$ and silver nanoparticles (AgNPs). Anal Chem. 2019;91:3359-66.

38. Fan Y, Shi SY, Ma JS, Guo YH. A paper-based electrochemical immunosensor with reduced graphene oxide/thionine/gold nanoparticles nanocomposites modification for the detection of cancer antigen 125. Biosens Bioelectron. 2019;135:1-7.

39. Liu P, Li BW, Fu LW, Huang Y, Man MS, Qi J, Sun XY, Kang Q, Shen DZ, Chen LX. Hybrid three dimensionally printed paperbased microfluidic platform for investigating a cell's apoptosis and intracellular cross-talk. ACS Sen. 2020;5:464-73.

40. Kou XX, Tong LJ, Shen YJ, Zhu WS, Yin L, Huang SM, Zhu F, Chen GS, Ouyang GF. Smartphone-assisted robust enzymes@ MOFs-based paper biosensor for point-of-care detection. Biosens Bioelectron. 2020;156:112095.

41. Al Lawati HAJ, Hassanzadeh J. Dual-function 2D cobalt metalorganic framework embedded on paper as a point-of-care diagnostic device: application for the quantification of glucose. Anal Chim Acta. 2020;1139:15-26.

42. Xia ZP, Li D, Deng W. Identification and detection of volatile aldehydes as lung cancer biomarkers by vapor generation combined with paper-based thin-film microextraction. Anal Chem. 2021;93:4924-31.

43. Petryayeva E, Algar WR. Multiplexed homogeneous assays of proteolytic activity using a smartphone and quantum dots. Anal Chem. 2014;86:3195-202.
44. Frantz E, Li H, Steckl AJ. Quantitative hematocrit measurement of whole blood in a point-of-care lateral flow device using a smartphone flow tracking app. Biosens Bioelectron. 2020;163:112300.

45. Park CY, Kim H-R, Kim S-K, Jeong I-K, Pyun J-C, Park S. Three-dimensional paper-based microfluidic analytical devices integrated with a plasma separation membrane for the detection of biomarkers in whole blood. ACS Appl Mater Interfaces. 2019;11:36428-34.

46. Samara B, Deliorman M, Sukumar P, Qasaimeh MA. Cryopreservable arrays of paper-based 3D tumor models for high throughput drug screening. Lab Chip. 2021;21:844-54.

47. Nguyen QH, Kim MI. Nanomaterial-mediated paper-based biosensors for colorimetric pathogen detection. Trends Anal Chem. 2020;132:116038.

48. Veloso AJ, Hung VWS, Sindhu G, Constantinof A, Kerman K. Electrochemical oxidation of benzothiazole dyes for monitoring amyloid formation related to the alzheimer's disease. Anal Chem. 2009;81:9410-5.

49. Silva-Neto HA, Cardoso TMG, McMahon CJ, Sgobbi LF, Henry CS, Coltro WKT. Plug-and-play assembly of paper-based colorimetric and electrochemical devices for multiplexed detection of metals. Analyst. 2021;146:3463.

50. Meredith NA, Quinn C, Cate DM, Reilly TH, Volckens J, Henry CS. Paper-based analytical devices for environmental analysis. Analyst. 2016;141:1874-87.

51. Jin B, Yang Y, He R, Park YI, Lee A, Bai D, Li F, Lu TJ, Xu F, Lin M. Lateral flow aptamer assay integrated smartphone-based portable device for simultaneous detection of multiple targets using upconversion nanoparticles. Sens Actuators B Chem. 2018;276:48-56.

52. Liang B, Cao QP, Mao XY, Pan WH, Tu TT, Fang L. An integrated paper-based microfluidic device for real-time sweat potassium monitoring. IEEE Sens J. 2021;21:9642-8.

53. Yoon JH, Kim KH, Bae NH, Sim GS, Oh Y-J, Lee SJ, Lee TJ, Lee KG, Choi BG. Fabrication of newspaper-based potentiometric platforms for flexible and disposable ion sensors. Colloid Interf J Sci. 2017;508:167-73.

54. Channon RB, Nguyen MP, Scorzelli AG, Henry EM, Volckens J, Dandy DS, Henry CS. Rapid flow in multilayer microfluidic paper-based analytical devices. Lab Chip. 2018;18:793-802.

55. Ming T, Wang Y, Luo JP, Liu JT, Sun SA, Xing Y, Xiao GH, Jin HY, Cai XX. Folding paper-based aptasensor platform coated with novel nanoassemblies for instant and highly sensitive detection of $17 \beta$-estradiol. ACS Sens. 2019;4:3186-94.

56. Martins GV, Marques AC, Fortunato E, Sales MGF. Waxprinted paper-based device for direct electrochemical detection of 3-nitrotyrosine. Electrochim Acta. 2018;284:60-8.

57. Wang F, Fan QF, Wang YH, Ge SG, Yan M, Yu JH. A paper-supported photoelectrochemical sensing platform based on surface plasmon resonance enhancement for real-time $\mathrm{H}_{2} \mathrm{~S}$ determination. J Anal Test. 2019;3:89-98.

58. Chaiyo S, Mehmeti E, Siangproh W, Hoang TL, Nguyene HP, Chailapakul O, Kalcher K. Non-enzymatic electrochemical detection of glucose with a disposable paper-based sensor using a cobalt phthalocyanine-ionic liquid-graphene composite. Biosens Bioelectron. 2018;102:113-20.

59. Sarwar M, Rodriguez P, Li CZ. Sweat-based in vitro diagnostics (IVD): from sample collection to point-of-care testing (POCT). J Anal Test. 2019;3:80-8.

60. Cinti S, Cusenza R, Moscone D, Arduini F. Paper-based synthesis of prussian blue nanoparticles for the development of whole blood glucose electrochemical biosensor. Talanta. 2018;187:59-64.

61. Ahmadi A, Khoshfetrat SM, Kabiri S, Fotouhi L, Dorraji PS, Omidfar K. Impedimetric paper-based enzymatic biosensor using 
electrospun cellulose acetate nanofiber and reduced graphene oxide for detection of glucose from whole blood. IEEE Sens J. 2021;21:9210-7.

62. Xu W, Fu KY, Bohn PW. Electrochromic sensor for multiplex detection of metabolites enabled by closed bipolar electrode coupling. ACS Sens. 2017;2:1020-6.

63. Li YC, He RG, Niu Y, Li F. Paper-based electrochemical biosensors for point-of-care testing of eurotransmitters. J Anal Test. 2019;3:19-36.

64. Lu Q, Su T, Shang ZJ, Jin DQ, Shu Y, Xu Q, Hu XY. Flexible paper-based Ni-MOF composite/AuNPs/CNTs film electrode for HIV DNA detection. Biosens Bioelectron. 2021;184:113229.

65. Narang J, Singhal C, Mathur A, Sharma S, Singla V, Pundir CS. Portable bioactive paper based genosensor incorporated with $\mathrm{Zn}-\mathrm{Ag}$ nanoblooms for herpes detection at the point-of-care. Int J Biol Macromol. 2018;107:2559-65.

66. Cinti S, Proietti E, Casotto F, Moscone D, Arduini F. Paperbased strips for the electrochemical detection of single and double stranded DNA. Anal Chem. 2018;90:13680-6.

67. Qi J, Li BW, Zhou N, Wang XY, Deng DM, Luo LQ, Chen LX. The strategy of antibody-free biomarker analysis by in-situ synthesized molecularly imprinted polymers on movable valve paper-based device. Biosens Bioelectron. 2019;142:111533.

68. Kaushik A, Tiwari S, Jayant RD, Marty A, Nair M. Towards detection and diagnosis of ebola virus disease at point-of-care. Biosens Bioelectron. 2016;75:254-72.

69. Cao LL, Fang C, Zeng RS, Zhao XJ, Jiang YR, Chen ZC. Paperbased microfluidic devices for electrochemical immunofiltration analysis of human chorionic gonadotropin. Biosens Bioelectron. 2017;92:87-94.

70. Honikel MM, Lin CE, Cardinell BA, LaBelle JT, Penman AD. Direct measurement of a biomarker's native optimal frequency with physical adsorption based immobilization. ACS Sens. 2018;3:823-31.

71. Li X, Liu XY. A Microfluidic Paper-based origami nanobiosensor for label-free, ultrasensitive immunoassays. Adv Healthcare Mater. 2016;5:1326-35.

72. Wang Y, Xu H, Luo JP, Liu JT, Wang L, Fan Y, Yan S, Yang Y, Cai XX. A novel label-free microfluidic paper-based immunosensor for highly sensitive electrochemical detection of carcinoembryonic antigen. Biosens Bioelectron. 2016;83:319-26.

73. Wang Y, Luo JP, Liu JT, Sun S, Xiong Y, Ma YY, Yan S, Yang Y, Yin HB, Cai XX. Label-free microfluidic paper-based electrochemical aptasensor for ultrasensitive and simultaneous multiplexed detection of cancer biomarkers. Biosens Bioelectron. 2019;136:84-90.

74. González-López A, Blanco-López MC, Fernández-Abedul MT. Micropipette-tip based immunoassay with electrochemical detection of anti-tissue transglutaminase to diagnose celiac disease using staples and a paper-based platform. ACS Sens. 2019;4:2679-87.

75. Zheng XX, Cuin K, Zhang Y, Zhang L, Ge SG, Yu JH. Ultrasensitive enzyme-free biosensor by coupling cyclodextrin functionalized Au nanoparticles and high-performance Au-paper electrode. ACS Appl Mater Interfaces. 2018;10:3333-40.

76. Wei B, Mao K, Liua N, Zhang M, Yang ZG. Graphene nanocomposites modified electrochemical aptamer sensor for rapid and highly sensitive detection of prostate specific antigen. Biosens Bioelectron. 2018;121:41-6.

77. Yakoh A, Pimpitak U, Rengpipat S, Hirankarn N, Chailapakul O, Chaiyo S. Paper-based electrochemical biosensor for diagnosing COVID-19: detection of SARS-CoV-2 antibodies and antigen. Biosens Bioelectron. 2021;176:112912.

78. Channon RB, Yang YY, Feibelman KM, Geiss BJ, Dandy DS, Henry CS. Development of an electrochemical paper-based analytical device for trace detection of virus particles. Anal Chem. 2018;90:7777-83.

79. Zhang XB, Zhi H, Zhu MZ, Wang FY, Meng H, Feng L. Electrochemical/visual dual-readout aptasensor for ochratoxin a detection integrated into a miniaturized paper-based analytical device. Biosens Bioelectron. 2021;180:113146.

80. Trieu PT, Lee NY. Paper-based all-in-one origami microdevice for nucleic acid amplification testing for rapid colorimetric identification of live cells for point-of-care testing. Anal Chem. 2019;91:11013-22.

81. Li ZD, Li F, Xing Y, Liu Z, You ML, Li YC, Wen T, Qu ZG, Li $\mathrm{XL}, \mathrm{Xu}$ F. Pen-on-paper strategy for point-of-care testing: rapid prototyping of fully written microfluidic biosensor. Biosens Bioelectron. 2017;98:478-85.

82. Chen MY, Ning ZQ, Chen KY, Zhang YJ, Shen YF. Recent advances of electrochemiluminescent system in bioassay. J Anal Test. 2020;4:57-75.

83. Zhou T, Huang R, Huang MQ, Shen JJ, Shan YY, Xing D. CRISPR/Cas 13a powered portable electrochemiluminescence chip for ultrasensitive and specific miRNA detection. Adv Sci. 2020;7:1903661.

84. Ge SG, Zhao JG, Wang SP, Lan FF, Yan M, Yu JH. Ultrasensitive electrochemiluminescence assay of tumor cells and evaluation of $\mathrm{H}_{2} \mathrm{O}_{2}$ on a paper-based closed-bipolar electrode by in-situ hybridization chain reaction amplification. Biosens Bioelectron. 2018;102:411-7.

85. Yang HM, Zhang Y, Li L, Zhang LN, Lan FF, Yu JH. Sudokulike lab-on-paper cyto-device with dual enhancement of electrochemiluminescence intermediates strategy. Anal Chem. 2017;89:7511-9.

86. Huang YZ, Li L, Zhang Y, Zhang LN, Ge SG, Yu JH. Autocleaning paper-based electrochemiluminescence biosensor coupled with binary catalysis of cubic $\mathrm{Cu}_{2} \mathrm{O}-\mathrm{Au}$ and polyethyleneimine for quantification of $\mathrm{Ni}^{2+}$ and $\mathrm{Hg}^{2+}$. Biosens Bioelectron. 2019;126:339-45.

87. Sun XG, Li BW, Tian CY, Yu FB, Zhou N, Zhan YH, Chen LX. Rotational paper-based electrochemiluminescence immunodevices for sensitive and multiplexed detection of cancer biomarkers. Anal Chem Acta. 2018;1007:33-9.

88. Huang YZ, Zhang LN, Zhang SB, Zhao PN, Li L, Ge SG, Yu JH. Paper-based electrochemiluminescence determination of streptavidin using reticular DNA-functionalized $\mathrm{PtCu}$ nanoframes and analyte-triggered DNA walker. Microchim Acta. 2020;187:530.

89. Qi LM, Xia Y, Qi WJ, Gao WY, Wu FX, Xu GB. Increasing electrochemiluminescence intensity of a wireless electrode array chip by thousands of times using a diode for sensitive visual detection by a digital camera. Anal Chem. 2016;88:1123-7.

90. Wang FF, Liu YQ, Fu CP, Li N, Du M, Zhang LN, Ge SG, $\mathrm{Yu}$ JH. Paper-based bipolar electrode electrochemiluminescence platform for detection of multiple miRNAs. Anal Chem. 2021;93:1702-8.

91. Wang FF, Fu CP, Huang C, Li N, Wang YH, Ge SG, Yu JH. Paper-based closed Au-bipolar electrode electrochemiluminescence sensing platform for the detection of miRNA-155. Biosens Bioelectron. 2020;150:111917.

92. Liu F, Ge SG, Su M, Song XR, Yan M, Yu JH. Electrochemiluminescence device for in-situ and accurate determination of CA153 at the MCF-7 cell surface based on graphene quantum dots loaded surface villous Au nanocage. Biosens Bioelectron. 2015;71:286-93.

93. Wu LD, Zhang Y, Wang YH, Ge SG, Liu HY, Yan M, Yu JH. A paper-based electrochemiluminescence electrode as an aptamerbased cytosensor using PtNi@carbon dots as nanolabels for detection of cancer cells and for in-situ screening of anticancer drugs. Microchim Acta. 2016;183:1873-80. 
94. Zhang HR, Wang YZ, Zhao W, Xu JJ, Chen HY. Visual colorswitch electrochemiluminescence biosensing of cancer cell based on multichannel bipolar electrode chip. Anal Chem. 2016;88:2884-90.

95. Ino K, Yaegaki R, Hiramoto K, Nashimoto Y, Shiku H. Closed bipolar electrode array for on-chip analysis of cellular respiration by cell aggregates. ACS Sens. 2020;5:740-5.

96. Zhang Y, Xu JM, Zhou S, Zhu L, Lv X, Zhang J, Zhang LN, Zhu PH, Yu JH. DNAzyme-triggered visual and ratiometric electrochemiluminescence dual-readout assay for $\mathrm{Pb}(\mathrm{II})$ based on an assembled paper device. Anal Chem. 2020;92:3874-81.

97. Huang YZ, Li L, Zhang Y, Zhang LN, Ge SG, Li H, Yu JH. Cerium dioxide-mediated signal "on-off" by resonance energy transfer on a lab-on-paper device for ultrasensitive detection of lead ions. ACS Appl Mater Interfaces. 2017;9:32591-8.

98. Zhang LN, Li L, Ma C, Ge SG, Yan M, Bian CR. Detection of $\alpha$-fetoprotein with an ultrasensitive electrochemiluminescence paper device based on green-luminescent nitrogendoped graphene quantum dots. Sens Actuators B Chem. 2015;221:799-806.

99. Liu Y, Fan ZJ, Zhou Y, Lin JY, Yang Y, Yan L, Li YL, Jiang L, Yang F, Hu QY, Yu J, Chen LY, Liao YH. Self-circulating electrochemiluminescence chip for sensitive detection of circulating tumour nucleic acids in blood. Sens Actuators B Chem. 2019;301:127088.

100. Zhang X, Ding SN. Graphite paper-based bipolar electrode electrochemiluminescence sensing platform. Biosens Bioelectron. 2017;94:47-55.

101. Xiao Y, Xu LR, Li P, Tang XC, Qi LW. A simple microdroplet chip consisting of silica nanochannel-assisted electrode and paper cover for highly sensitive electrochemiluminescent detection of drugs in human serum. Anal Chem Acta. 2017;983:96-102.

102. Xiao Y, Xu LR, Qi LW. Electrochemiluminescence bipolar electrode array for the multiplexed detection of glucose, lactate and choline based on a versatile enzymatic approach. Talanta. 2017;165:577-83.

103. Feng QM, Chen HY, Xu JJ. Disposable paper-based bipolar electrode array for multiplexed electrochemiluminescence detection of pathogenic DNAs. Sci China Chem. 2015;58:810-8.

104. Hamedi MM, Ünal B, Kerr E, Glavan AC, Abedul MTF, Whitesides GM. Coated and uncoated cellophane as materials for microplates and open-channel microfluidics devices. Lab Chip. 2016;16:3885-97.

105. Mujawar LH, El-Shahawi MS. Rapid and sensitive microassay for trace determination and speciation of $\mathrm{Cu}^{2+}$ on commercial book-paper printed with nanolitre arrays of novel chromogenic reagent. Microchem J. 2019;146:434-43.

106. Lee YF, Deng TW, Chiu WJ, Wei TY, Roy P, Huang CC. Visual detection of copper(ii) ions in blood samples by controlling the leaching of protein-capped gold nanoparticles. Analyst. 2012;137:1800-6.

107. Wu C, Gao GZ, Zhai KF, Xu LS, Zhang DG. A visual $\mathrm{Hg}^{2+}$ detection strategy based on distance as readout by G-quadruplex DNAzyme on microfluidic paper. Food Chem. 2020;331:127208.

108. Faham S, Khayatian G, Golmohammadi H, Ghavami R. A paperbased optical probe for chromium by using gold nanoparticles modified with 2,2'-thiodiacetic acid and smartphone camera readout. Microchim Acta. 2018;185:374.

109. Liu GK, Peng JJ, Zheng H, Yuan DX. Developing on-site paper colorimetric monitoring technique for quick evaluating copper ion concentration in mineral wastewater. Spectrochim Acta A. 2018;196:392-7.

110. Huang K, Dai R, Deng WQ, Guo SJ, Deng H, Wei Y, Zhou FL, Long Y, Li J, Yuan X, Xiong XL. Gold nanoclusters immobilized paper for visual detection of zinc in whole blood and cells by coupling hydride generation with headspace solid phase extraction. Sens Actuators B Chem. 2018;255:1631-9.

111. Hu L, Zhu BH, Zhang L, Yuan H, Zhao Q, Yan ZQ. Chitosangold nanocomposite and its functionalized paper strips for reversible visual sensing and removal of trace $\mathrm{Hg}^{2+}$ in practice. Analyst. 2019;144:474-80.

112. Kirk KA, Andreescu S. Easy-to-use sensors for field monitoring of copper contamination in water and pesticide-sprayed plants. Anal Chem. 2019;91:13892-9.

113. Hou CY, Fu LM, Ju WJ, Wu PY. Microfluidic colorimetric system for nitrite detection in foods. Chem Eng J. 2020;398:125573.

114. Dong RE, Kang P, Xu XL, Cai LX, Guo Z. Cation-exchange strategy for a colorimetric paper sensor: belt-like ZnSe nanoframes toward visual determination of heavy metal ions. Sens Actuators B Chem. 2020;312:128013.

115. Li WY, Lu SY, Bao SJ, Shi ZZ, Lu ZS, Li CM, Yu L. Efficient in situ growth of enzyme-inorganic hybrids on paper strips for the visual detection of glucose. Biosens Bioelectron. 2018;99:603-11.

116. Gong FW, Wei HX, Qi J, Ma H, Liu LX, Weng JP, Zheng XC, Li QS, Zhao D, Fang HP, Liu L, He HL, Ma CC, Han JL, Sun AY, Wang BL, Jin TC, Li BW, Li BF. Pulling-force spinning top for serum separation combined with paper-based microfluidic devices in COVID-19 ELISA diagnosis. ACS Sens. 2021;6:2709-19.

117. Li BW, Qi J, Fu LW, Han JL, Choo J, deMello AJ, Lin BC, Chen LX. Integrated hand-powered centrifugation and paperbased diagnosis with blood-in/answer-out capabilities. Biosens Bioelectron. 2020;165:112282.

118. Pinheiro T, Ferrão J, Marques AC, Oliveira MJ, Batra NM, Costa PMFJ, Macedo MP, Águas H, Martins R, Fortunato E. Paper-based in-situ gold nanoparticle synthesis for colorimetric, non-enzymatic glucose level determination. Nanomaterials. 2020;10:2027.

119. Zhang H, Chen Z, Dai J, Zhang W, Jiang Y, Zhou A. A low-cost mobile platform for whole blood glucose monitoring using colorimetric method. Microchem J. 2021;162:105814.

120. Mahato K, Chandra P. Paper-based miniaturized immunosensor for naked eye ALP detection based on digital image colorimetry integrated with smartphone. Biosens Bioelectron. 2019;128:9-16.

121. Liu W, Guo YM, Zhao M, Li HF, Zhang ZJ. Ring-oven washing technique integrated paper-based immunodevice for sensitive detection of cancer biomarker. Anal Chem. 2015;87:7951-7.

122. Alizadeh N, Salimi A, Hallaj R. Mimicking peroxidase activity of $\mathrm{Co}_{2}(\mathrm{OH})_{2} \mathrm{CO}_{3}{ }^{-} \mathrm{CeO}_{2}$ nanocomposite for smartphone based detection of tumor marker using paper-based microfluidic immunodevice. Talanta. 2018;189:100-10.

123. Zhang P, Zhang CS, Shu BW. Micropatterned paper devices using amine-terminated polydiacetylene vesicles as colorimetric probes for enhanced detection of double-stranded DNA. Sens Actuators B Chem. 2016;236:27-34.

124. Singh NK, Jain P, Das S, Goswami P. Dye coupled aptamercaptured enzyme catalyzed reaction for detection of pan malaria and $\mathrm{p}$. falciparum species in laboratory settings and instrumentfree paper-based platform. Anal Chem. 2019;91:4213-21.

125. Chen CA, Wang PW, Yen YC, Lin HL, Fan YC, Wu SM, Chen CF. Fast analysis of ketamine using a colorimetric immunosorbent assay on a paper-based analytical device. Sens Actuators B Chem. 2019;282:251-8.

126. Hongwarittorrn I, Chaichanawongsaroj N, Laiwattanapaisal W. Semi-quantitative visual detection of loop mediated isothermal amplification (LAMP)-generated DNA by distance-based measurement on a paper device. Talanta. 2017;175:135-42.

127. Xiong EH, Jiang L, Tian T, Hu ML, Yue HH, Huang MQ, Lin W, Jiang YZ, Zhu DB, Zhou XM. Simultaneous dual-gene diagnosis 
of SARS-CoV-2 based on CRISPR/Cas9-mediated lateral flow assay. Angew Chem Int Edit. 2021;60:5307-15.

128. Zhang SN, Cai Y, Zhang JX, Liu XN, He LH, Cheng L, Hua K, Hui WL, Zhu JL, Wan YS, Cui YL. Tetra-primer ARMSPCR combined with goldmag lateral flow assay for genotyping: simultaneous visual detection of both alleles. Nanoscale. 2020;12:10098-105.

129. Jauset-Rubio M, Tomaso H, El-Shahawi MS, Bashammakh AS, Al-Youbi AO, O'Sullivan CK. Duplex lateral flow assay for the simultaneous detection of yersinia pestis and francisella tularensis. Anal Chem. 2018;90:12745-51.

130. Teengam P, Siangproh W, Tuantranont A, Vilaivan T, Chailapakul O, Henry CS. Multiplex paper-based colorimetric DNA sensor using pyrrolidinyl peptide nucleic acid-induced AgNPs aggregation for detecting MERS-CoV, MTB, and HPV oligonucleotides. Anal Chem. 2017;89:5428-35.

131. Song YJ, Gyarmati P. Visual detection of bacterial DNA using activated paper stripe. Microchim Acta. 2019;186:642.

132. Chen WW, Fang XE, Li H, Cao HM, Kong JL. DNA-mediated inhibition of peroxidase-like activities on platinum nanoparticles for simple and rapid colorimetric detection of nucleic acids. Biosens Bioelectron. 2017;94:169-75.

133. Phoonsawat K, Dungchaia W. Highly sensitive, selective and naked-eye detection of bromide and bromate using distancebased paper analytical device. Talanta. 2021;221:121590.

134. Zhang DG, Wu C, Luan CX, Gao P, Wang H, Chi JJ, Kong TT. Distance-based quantification of miRNA-21 by the coffee-ring effect using paper devices. Microchim Acta. 2020;187:513.

135. Rahbar M, Wheeler AR, Paull B, Macka M. Ion-exchange based immobilization of chromogenic reagents on microfluidic paper analytical devices. Anal Chem. 2019;91:8756-61.

136. Abate MF, Ahmed MG, Li XR, Yang CY, Zhu Z. Distance-based paper/PMMA integrated ELISA-chip for quantitative detection of immunoglobulin G. Lab Chip. 2020;20:3625-32.

137. Hossain SMZ, Ozimok C, Sicard C, Aguirre S, Ali MM, Li Y, Brennan J. Multiplexed paper test strip for quantitative bacterial detection. Anal Bioanal Chem. 2012;403:1567-76.

138. Gorbunova MO, Baulina AA, Kulyaginova MS, Apyari VV, Furletov AA, Volkov PA, Bochenkov VE, Starukhin AS, Dmitrienko SG. Dynamic gas extraction of iodine in combination with a silver triangular nanoplate-modified paper strip for colorimetric determination of iodine and of iodine-interacting compounds. Microchim Acta. 2019;186:188-96.

139. Ma Y, Mao Y, Huang D, He Z, Yan J, Tian T, Shi Y, Song Y, Li $\mathrm{X}, \mathrm{Zhu} \mathrm{Z}$. Portable visual quantitative detection of aflatoxin $\mathrm{B}_{1}$ using a target-responsive hydrogel and a distance-readout microfluidic chip. Lab Chip. 2016;16:3097-104.

140. Zhu Z, Guan Z, Jia S, Lei Z, Lin S, Zhang H, Ma Y, Tian ZQ, Yang CJ. Au@Pt nanoparticle encapsulated target-responsive hydrogel with volumetric bar-chart chip readout for quantitative point-of-care testing. Angew Chem Int Ed. 2014;53:12503-7.

141. Chen Y, Chu WR, Liu W, Guo XY. Distance-based carcinoembryonic antigen assay on microfluidic paper immunodevice. Sens Actuators B Chem. 2018;260:452-9.

142. Khachornsakkul K, Dungchai W. Rapid distance-based cardiac troponin quantification using paper analytical devices for the screening and the follow-up of acute myocardial infarction, using a single drop of human whole blood. ACS Sens. 2021;6:1339-47.

143. Jauset-Rubio M, El-Shahawi MS, Bashammakh AS, Alyoubi AO, O'Sullivan CK. Advances in aptamers-based lateral flow assays. Trends Anal Chem. 2017;97:385-98.

144. Soh JH, Chan HM, Ying JY. Strategies for developing sensitive and specific nanoparticle-based lateral flow assays as point-ofcare diagnostic device. Nano Today. 2020;30:100831.

145. Guler E, Sengel TY, Gumus ZP, Arslan M, Coskunol H, Timur $\mathrm{S}$, Yagci Y. Mobile phone sensing of cocaine in a lateral flow assay combined with a biomimetic material. Anal Chem. 2017;89:9629-32.

146. Chen XL, Deng YY, Cao GH, Liu XY, Gu T, Feng RY, Huo DQ, Xu FL, Hou CJ. Simultaneous detection of serum glucose and glycated albumin on a paper-based sensor for acute hyperglycemia and diabetes mellitus. Anal Chem. 2020;92:11530-4.

147. Chen XL, Deng YY, Cao GH, Liu XY, Gu T, Feng RY, Huo DQ, Xu FL, Hou CJ. An ultrasensitive and point-of-care sensor for the telomerase activity detection. Anal Chim Acta. 2021;1146:61-9.

148. Grant BD, Anderson CE, Williford JR, Alonzo LF, Glukhova VA, Boyle DS, Weigl BH, Nichols KP. SARS-CoV-2 coronavirus nucleocapsid antigen-detecting half-strip lateral flow assay toward the development of point of care tests using commercially available reagents. Anal Chem. 2020;92:11305-9.

149. Magiati M, Myridaki VM, Christopoulos TK, Kalogianni DP. Lateral flow test for meat authentication with visual detection. Food Chem. 2019;274:803-7.

150. Guo XR, Yuan Y, Liu JL, Fu S, Zhang J, Mei QS, Zhang Y. Single-line flow assay platform based on orthogonal emissive upconversion nanoparticles. Anal Chem. 2021;93:3010-7.

151. Frohnmeyer E, Tuschel N, Sitz T, Hermann C, Dahl GT, Schulz F, Baeumner AJ, Fischer M. Aptamer lateral flow assays for rapid and sensitive detection of cholera toxin. Analyst. 2019;144:1840-9.

152. Hu QS, Wei QZ, Zhang PP, Li S, Xue L, Yang RF, Wang CB, Zhou L. An up-converting phosphor technology-based lateral flow assay for point-of-collection detection of morphine and methamphetamine in saliva. Analyst. 2018;143:4646-54.

153. Pratt GW, Fan A, Melakeberhan B, Klapperich CM. A competitive lateral flow assay for the detection of tenofovir. Anal Chem Acta. 2018;1017:34-40.

154. Patel S, Jamunkar R, Sinha D, Monisha S, Patle TK, Kant T, Dewangan K, Shrivas K. Recent development in nanomaterials fabricated paper-based colorimetric and fluorescent sensors: a review. Trends Environ Anal Chem. 2021;31:e00136.

155. Yang LL, Wang JP, Yang L, Zhang C, Zhang RL, Zhang ZP, Liu $\mathrm{BH}$, Jiang CL. Fluorescent paper sensor fabricated by carbazolebased probes for dual visual detection of $\mathrm{Cu}^{2+}$ and gaseous $\mathrm{H}_{2} \mathrm{~S}$. RSC Adv. 2016;6:56384-91.

156. Zhou YJ, Huang XY, Liu C, Zhang RL, Gu XL, Guan GJ, Jiang CL, Zhang LY, Du SH, Liu BH, Han MY, Zhang ZP. Colormultiplexing-based fluorescent test paper: dosage-sensitive visualization of arsenic(III) with discernable scale as low as $5 \mathrm{ppb}$. Anal Chem. 2016;88:6105-9.

157. Tian Y, Xin CQ, Fang ZL, Fang XD, Zhou J, Yu HD, Li L, Ju Q. Thinning shell thickness of $\mathrm{CuInS}_{2} @ \mathrm{ZnS}$ quantum dots to boost detection sensitivity. Anal Chem Acta. 2019;1047:124-30.

158. Khoshbin Z, Housaindokht MR, Izadyar M, Verdian A, Bozorgmehr MR. A simple paper-based aptasensor for ultrasensitive detection of lead (II) ion. Anal Chem Acta. 2019;1071:70-7.

159. Chen HY, Hu O, Fu HY, Fan Y, Xu L, Meng QJ, Zhang L, Lan $\mathrm{W}, \mathrm{Wu}$ CY, Tang SY, She YB. Paper-based sensor for visual detection of $\mathrm{Ag}^{+}$based on a "turn-off-on" fluorescent design. Microchem J. 2020;157:104887.

160. Xiao M, Liu ZG, Xu NX, Jiang LL, Yang MS, Yi CQ. A smartphone-based sensing system for on-site quantitation of multiple heavy metal ions using fluorescent carbon nanodots-based microarrays. ACS Sens. 2020;5:870-8.

161. Hajinia A, Heidari T. Sensitive fluorometric determination of gold in geological samples using fire assay pre-concentration coupled with microfluidic paper-based analytical device. Microchem J. 2021;164:105923.

162. Maruthupandi M, Thiruppathi D, Vasimalai N. One minute synthesis of green fluorescent copper nanocluster: the preparation of smartphone aided paper-based kit for on-site monitoring of 
nanomolar level mercury and sulfide ions in environmental samples. Hazard J Mater. 2020;392:122294.

163. Chen XC, Yu SM, Yang L, Wang JP, Jiang CL. Fluorescence and visual detection of fluoride ions using a photoluminescent graphene oxide paper sensor. Nanoscale. 2016;8:13669-77.

164. İncel $\mathrm{A}, \mathrm{Akın} \mathrm{O}$, Çağır $\mathrm{A}, \mathrm{Y}$ ıldız ÜH, Demir MM. Smart phone assisted detection and quantification of cyanide in drinking water by paper based sensing platform. Sens Actuators B Chem. 2017;252:886-93.

165. Yang C, Feng WJ, Li Y, Tian XK, Zhou ZX, Lu LQ, Nie YL, Photoch J. Graphene oxide based ratiometric fluorescent paper sensor for hypochlorous acid visual detection. Photobio A Chem. 2019;375:141-7.

166. El-Shaheny R, Yoshida S, Fuchigami T. Graphene quantum dots as a nanoprobe for analysis of o- and p-nitrophenols in environmental water adopting conventional fluorometry and smartphone image processing-assisted paper-based analytical device. In-depth study of sensing mechanisms. Microchem J. 2020;158:105241.

167. Tian XK, Peng H, Li Y, Yang C, Zhou ZX, Wang YX. Highly sensitive and selective paper sensor based on carbon quantum dots for visual detection of TNT residues in groundwater. Sens Actuators B Chem. 2017;243:1002-9.

168. Hong CY, Ye SS, Dai CY, Wu CY, Chen LL, Huang ZY. Sensitive and on-site detection of glyphosate based on papainstabilized fluorescent gold nanoclusters. Anal Bioanal Chem. 2020;412:8177-84.

169. Cai YQ, You JH, You ZY, Dong F, Du SH, Zhang LY. Profuse color-evolution-based fluorescent test paper sensor for rapid and visual monitoring of endogenous $\mathrm{Cu}^{2+}$ in human urine. Biosens Bioelectron. 2018;99:332-7.

170. Zhang HL, Gao YF, Jiao Y, Lu WJ, Shuang SM, Dong C. Highly sensitive fluorescent carbon dots probe with ratiometric emission for the determination of $\mathrm{ClO}^{-}$. Analyst. 2020;145:2212-8.

171. Seo H, Singha S, Ahn KH. Ratiometric fluorescence detection of anthrax biomarker with Eu ${ }^{\mathrm{III}}$-EDTA functionalized mixed poly(diacetylene) liposomes. Asian J Org Chem. 2017;6:1257-63.

172. Rong MC, Liang YC, Zhao DL, Chen BJ, Pan C, Deng XZ, Chen YB, He J. A ratiometric fluorescence visual test paper for an anthrax biomarker based on functionalized manganese-doped carbon dots. Sens Actuators B Chem. 2018;265:498-505.

173. Chen HY, Liu R, Guo XM, Deng GQ, Xu L, Zhang L, Lan W, Zhou CS, She YB, Fu HY. Visual paper-based sensor for the highly sensitive detection of caffeine in food and biological matrix based on CdTe-nano ZnTPyP combined with chemometrics. Microchim Acta. 2021;188:27.

174. Qu YY, Yu LY, Zhu BY, Chai F, Su ZM. Green synthesis of carbon dots by celery leaves for use as fluorescent paper sensors for the detection of nitrophenols. New J Chem. 2020;44:1500-7.

175. Ardalan S, Hosseinifard M, Vosough M, Golmohammadi H. Towards smart personalized perspiration analysis: an iot-integrated cellulose-based microfluidic wearable patch for smartphone fluorimetric multi-sensing of sweat biomarkers. Biosens Bioelectron. 2020;168:112450.

176. Salekin S, Bari MG, Raphael I, Forsthuber TG, Zhang JM. Early response index: a statistic to discover potential early stage disease biomarkers. BMC Bioinformatics. 2017;18:313-24.

177. Huang LT, Wang J, Wang QS, Tang DP, Lin Y. Distancedependent visual fluorescence immunoassay on CdTe quantum dot-impregnated paper through silver ion-exchange reaction. Microchim Acta. 2020;187:563.

178. Liu C, Luo YX, Wen HJ, Qi YX, Shi GY, Deng JJ, Zhou TS. Red-to-blue paper-based colorimetric sensor integrated with smartphone for point-of-use analysis of cerebral AChE upon $\mathrm{Cd}^{2+}$ exposure. Nanoscale. 2021;13:1283-90.
179. Zhang H, Zhao Z, Lei Z, Wang ZX. Sensitive detection of polynucleotide kinase activity by paper-based fluorescence assay with $\lambda$ exonuclease assistance. Anal Chem. 2016;88:11358-63.

180. Ma YX, Mao GB, Zhong YC, Wu GQ, Wu WJ, Zhan YH, He ZK, Huang WR. Highly sensitive ratiometric fluorescent paper sensor for the urine assay of cancer. Talanta. 2019;194:199-204.

181. Ou Q, Tawfik SM, Zhang XF, Lee Y-I. Novel, "turn on-off” paper sensor based on nonionic conjugated polythiophene-coated CdTe QDs for efficient visual detection of cholinesterase activity. Analyst. 2020;145:4305-13.

182. Qiu ZL, Shu J, Tang DP. Bioresponsive release system for visual fluorescence detection of carcinoembryonic antigen from mesoporous silica nanocontainers mediated optical color on quantum dot-enzyme-impregnated paper. Anal Chem. 2017;89:5152-60.

183. Guo XY, Chen Y, Zhang L, Liu W. An inkjet printing paperbased immunodevice for fluorescence determination of immunoglobulin G. Anal Methods. 2019;11:3452-9.

184. He MY, Shang N, Zhu QR, Xu J. Paper-based upconversion fluorescence aptasensor for the quantitative detection of immunoglobulin E in human serum. Anal Chem Acta. 2021;1143:93-100.

185. Wang W, Cai XY, Li QL, Yu XF, Zhang HM, Wang J, Zheng LL. Application of a microfluidic paper-based bioimmunosensor with laser-induced fluorescence detection in the determination of alpha-fetoprotein from serum of hepatopaths. Talanta. 2021;221:121660.

186. Magiati M, Sevastou A, Kalogianni DP. A fluorometric lateral flow assay for visual detection of nucleic acids using a digital camera readout. Microchim Acta. 2018;185:314

187. Liu MD, Zhao YX, Monshat H, Tang ZY, Wu ZW, Zhang QJ, Lu M. An iot-enabled paper sensor platform for real-time analysis of isothermal nucleic acid amplification tests. Biosens Bioelectron. 2020;169:112651.

188. Ali MM, Brown CL, Jahanshahi-Anbuhi S, Kannan B, Li YF, Filipe CDM, Brennan JD. A printed multicomponent paper sensor for bacterial detection. Sci Rep. 2017;7:12335.

189. Li HY, Lin HY, Lv WX, Gai PP, Li F. Equipment-free and visual detection of multiple biomarkers via an aggregation induced emission luminogen-based paper biosensor. Biosens Bioelectron. 2020;165:112336.

190. Zhou W, Feng ML, Valadez A, Li XJ. One-step surface modification to graft DNA codes on paper: the method, mechanism, and its application. Anal Chem. 2020;92:7045-53.

191. Cai XY, Zhang HM, Yu XF, Wang W. A microfluidic paperbased laser-induced fluorescence sensor based on duplex-specific nuclease amplification for selective and sensitive detection of miRNAs in cancer cells. Talanta. 2020;216:120996.

192. Shahmuradyan A, Moazami-Goudarzi M, Kitazume F, Espie GS, Krull UJ. Paper-based platform for detection by hybridization using intrinsically labeled fluorescent oligonucleotide probes on quantum dots. Analyst. 2019;144:1223-9.

193. Ulep TH, Zenhausern R, Gonzales A, Knoff DS, Diaz PAL, Castro JE, Yoon JY. Smartphone based on-chip fluorescence imaging and capillary flow velocity measurement for detecting ROR $1^{+}$ cancer cells from buffy coat blood samples on dual-layer paper microfluidic chip. Biosens Bioelectron. 2020;153:112042.

194. Wu MYC, Hsu MY, Chen SJ, Hwang DK, Yen TH, Cheng CM. Point-of-care detection devices for food safety monitoring: proactive disease prevention. Trends Biotechnol. 2017;35:288-300.

195. Zhang D, Zhang YC, Lu W, Le XX, Li P, Huang L, Zhang JW, Yang JT, Serpe MJ, Chen DD, Chen T. Fluorescent hydrogelcoated paper/textile as flexible chemosensor for visual and wearable mercury(II) detection. Adv Mater Technol. 2019;4:1800201.

196. Lert-itthiporn A, Srikritsadawong P, Choengchan N. Foldable paper-based analytical device for membraneless gas-separation 
and determination of iodate based on fluorescence quenching of gold nanoclusters. Talanta. 2021;221:121574.

197. Gao YF, Jiao Y, Zhang HL, Lu WJ, Liu Y, Han H, Gong XJ, Li L, Shuang SM, Dong C. One-step synthesis of a dual-emitting carbon dot-based ratiometric fluorescent probe for the visual assay of $\mathrm{Pb}^{2+}$ and $\mathrm{PPi}$ and development of a paper sensor. Mater J Chem B. 2019;7:5502-9.

198. Guzman JMCC, Tayo LL, Liu CC, Wang YN, Fu LM. Rapid microfluidic paper-based platform for low concentration formaldehyde detection. Sens Actuators B Chem. 2018;255:3623-9.

199. Xu J, Guo SL, Jia L, Zhu TH, Chen XZ, Zhao TQ. A smartphoneintegrated method for visual detection of tetracycline. Chem Eng J. 2021;416:127741.

200. Lin BX, Zhang TY, Xin XL, Wu D, Huang Y, Liu YW, Cao YJ, Guo ML, Yu Y. Europium(III) modified silicone nanoparticles for ultrasensitive visual determination of tetracyclines by employing a fluorescence color switch. Microchim Acta. 2019;186:442-51.

201. Han L, Fan YZ, Qing M, Liu SG, Yang YZ, Li NB, Luo HQ. Smartphones and test paper-assisted ratiometric fluorescent sensors for semi-quantitative and visual assay of tetracycline based on the target-induced synergistic effect of antenna effect and inner filter effect. ACS Appl Mater Interfaces. 2020;12:47099-107.

202. Mei QS, Jing HR, Li Y, Yisibashaer W, Chen J, Li BN, Zhang Y. Smartphone based visual and quantitative assays on upconversional paper sensor. Biosens Bioelectron. 2016;75:427-32.

203. Chu SY, Wang HQ, Ling X, Yu SM, Yang L, Jiang CL. A portable smartphone platform using a ratiometric fluorescent paper strip for visual quantitative sensing. ACS Appl Mater Interfaces. 2020;12:12962-71.

204. Chen HY, Hu O, Fan Y, Xu L, Zhang L, Lan W, Hu Y, Xie XR, Ma LX, She YB, Fu HY. Fluorescence paper-based sensor for visual detection of carbamate pesticides in food based on CdTe quantum dot and nano ZnTPyP. Food Chem. 2020;327:127075.

205. Li YX, Zhang K, Zhao JJ, Ji J, Ji C, Liu BH. A three-dimensional silver nanoparticles decorated plasmonic paper strip for SERS detection of low-abundance molecules. Talanta. 2016;147:493-500.

206. Wei X, Huang QL. Rapid fabrication of silver nanoparticlecoated filter paper as SERS substrate for low-abundance molecules detection. Spectrochim Acta A. 2017;179:211-5.

207. Lee JC, Kim W, Choi S. Fabrication of a SERS-encoded microfluidic paper-based analytical chip for the point-ofassay of wastewater. Int J Precis Eng Manuf-Green Technol. 2017;4:221-6.

208. Yang C, Xu YY, Wang MH, Li TM, Huo YY, Yang CX, Man BY. Multifunctional paper strip based on go-veiled Ag nanoparticles with highly SERS sensitive and deliverable properties for high-performance molecular detection. Opt Express. 2018;26:10023-37.

209. Koh EH, Mun CW, Kim CT, Park SG, Choi EJ, Kim SH, Dang J, Choo J, Oh JW, Kim DH, Jung HS. M13 bacteriophage/silver nanowire surface-enhanced raman scattering sensor for sensitive and selective pesticide detection. ACS Appl Mater Interfaces. 2018;10:10388-97.

210. Zhao P, Liu HY, Zhang LL, Zhu PH, Ge SG, Yu JH. Paper-based SERS sensing platform based on 3D silver dendrites and molecularly imprinted identifier sandwich hybrid for neonicotinoid quantification. ACS Appl Mater Interfaces. 2020;12:8845-54.

211. Liu RY, Jiang L, Yu ZZ, Jing XF, Liang X, Wang D, Yang B, Lu $\mathrm{CX}$, Zhou W, Jin SZ. MXene $\left(\mathrm{Ti}_{3} \mathrm{C}_{2} \mathrm{Tx}\right)$-Ag nanocomplex as efficient and quantitative SERS biosensor platform by in-situ PDDA electrostatic self-assembly synthesis strategy. Sens Actuators B Chem. 2021;333:129581.

212. Wang QZ, Liu YN, Bai YW, Yao SY, Wei ZJ, Zhang M, Wang LM, Wang L. Superhydrophobic SERS substrates based on silver dendrite-decorated filter paper for trace detection of nitenpyram. Anal Chem Acta. 2019;1049:170-8.

213. Sun L, Yu ZL, Alsammarraie FK, Lin MH, Kong F, Huang MZ, Lin MS. Development of cellulose nanofiber-based substrates for rapid detection of ferbam in kale by surface-enhanced Raman spectroscopy. Food Chem. 2021;347:129023.

214. Siebe HS, Chen QL, Li XY, Xu YK, Browne WR, Bell SEJ. Filter paper based SERS substrate for the direct detection of analytes in complex matrices. Analyst. 2021;146:1281-8.

215. Kim EJ, Kim H, Park E, Kim T, Chung DR, Choi YM, Kang M. Paper-based multiplex surface-enhanced raman scattering detection using polymerase chain reaction probe codification. Anal Chem. 2021;93:3677-85.

216. Maoa K, Yang ZG, Zhang H, Li XQ, Cooper M. Paper-based nanosensors to evaluate community-wide illicit drug use for wastewater-based epidemiology. Water Res. 2021;189:116559.

217. Villa JEL, Santos DP, Poppi RJ. Fabrication of gold nanoparticle-coated paper and its use as a sensitive substrate for quantitative SERS analysis. Microchim Acta. 2016;183:2745-52.

218. Xiao GN, Li YX, Shi WZ, Shen L, Chen Q, Huang L. Highly sensitive, reproducible and stable SERS substrate based on reduced graphene oxide/silver nanoparticles coated weighing paper. Appl Surf Sci. 2017;404:334-41.

219. Xu YY, Man PH, Huo YY, Ning TY, Li CH, Mana B, Yang C. Synthesis of the 3D AgNF/AgNP arrays for the paper-based surface enhancement raman scattering application. Sens Actuators B Chem. 2018;265:302-9.

220. Oh K, Lee M, Lee SG, Jung DH, Lee HL. Cellulose nanofibrils coated paper substrate to detect trace molecules using surfaceenhanced raman scattering. Cellulose. 2018;25:3339-50.

221. Geng ZQ, Zheng JJ, Li YP, Chen Y, Wang P, Han CQ, Yang $\mathrm{GH}, \mathrm{Qu}$ LL. A disposable paper-based hydrophobic substrate for highly sensitive surface-enhanced raman scattering detection. Talanta. 2020;220:121340.

222. Ma YD, Wang YH, Luo Y, Duan HZ, Li D, Xu H, Fodjo EK. Rapid and sensitive on-site detection of pesticide residues in fruits and vegetables using screen-printed paper-based SERS swabs. Anal Methods. 2018;10:4655-64.

223. Lan LL, Hou XY, Gao YM, Fan XC, Qiu T. Inkjet-printed paper-based semiconducting substrates for surface-enhanced raman spectroscopy. Nanotechnol. 2020;31:055502.

224. Das D, Senapati S, Nanda KK. "Rinse, Repeat": An efficient and reusable SERS and catalytic platform fabricated by controlled deposition of silver nanoparticles on cellulose paper. ACS Sustain Chem Eng. 2019;7:14089-101.

225. Wang JC, Qiu CC, Mu XJ, Pang H, Chen XC, Liu DM. Ultrasensitive SERS detection of rhodamine $6 \mathrm{G}$ and p-nitrophenol based on electrochemically roughened nano-Au film. Talanta. 2020;210:120631.

226. He DY, Wu ZZ, Cui B, Xu EB. Dual-mode aptasensor for SERS and chiral detection of campylobacter jejuni. Food Anal Methods. 2019;12:2185-93.

227. Zhang CM, You TT, Yang N, Gao YK, Jiang L, Yin PG. Hydrophobic paper-based SERS platform for direct-droplet quantitative determination of melamine. Food Chem. 2019;287:363-8.

228. Haddad A, Comanescu MA, Green O, Kubic TA, Lombardi JR. Detection and quantitation of trace fentanyl in heroin by surface-enhanced Raman spectroscopy. Anal Chem. 2018;90:12678-85.

229. Li D, Duan HZ, Ma YD, Deng W. Headspace-sampling paperbased analytical device for colorimetric/surface-enhanced raman scattering dual sensing of sulfur dioxide in wine. Anal Chem. 2018;90:5719-27.

230. Ameku WA, Araujo WR, Rangel CJ, Ando RA, Paixao TRLC. Gold nanoparticle paper-based dual-detection device for forensics applications. ACS Appl Nano Mater. 2019;2:5460-8. 
231. Gu CY, Zhao ZM, Shi PC. Development of monolayer AuNPs decorated on an optical fiber facet for SERS analysis. Appl Opt. 2021;60:792-8.

232. Díaz-Liñán MC, García-Valverde MT, López-Lorente AI, Cárdenas S, Lucena R. Silver nanoflower-coated paper as dual substrate for surface-enhanced raman spectroscopy and ambient pressure mass spectrometry analysis. Anal Bioanal Chem. 2020;412:3547-57.

233. Wu L, Zhang WM, Liu C, Fod MF, Zhu YH. Strawberry-like $\mathrm{SiO}_{2} / \mathrm{Ag}$ nanocomposites immersed filter paper as SERS substrate for acrylamide detection. Food Chem. 2020;328:127106.

234. Ngo TC, Trinh QT, An NTT, Tri NN, Trung NT, Truong DH, Huy BT, Nguyen MT, Dao DQ. SERS spectra of the pesticide chlorpyrifos adsorbed on silver nanosurface: the Ag20 cluster model. Phys J Chem C. 2020;124:21702-16.

235. Lv K, Si HP, Liu JJ, Zhu TY, Xia YP, Chen S, Zhao YF, Yang C, Alloy J. Plasmonic filters based on $\mathrm{MoS}_{2} @ \mathrm{Au} / \mathrm{Ag}$ hybrids: Controllable separation, preconcentration, and sensitive SERS detection. Compd. 2020;846:156438.

236. Chen M, Yang H, Rong LY, Chen XQ. A gas-diffusion microfluidic paper-based analytical device ( $\mu \mathrm{PAD}$ ) coupled with portable surface-enhanced raman scattering (SERS): facile determination of sulphite in wines. Analyst. 2016;141:5511-9.

237. Huang DQ, Zhuang ZF, Wang Z, Li ST, Zhong HQ, Liu ZM, Guo ZY, Zhang W. Black phosphorus-Au filter paper-based threedimensional SERS substrate for rapid detection of foodborne bacteria. Appl Surf Sci. 2019;497:143825.

238. Ilhan H, Guven B, Dogan U, Torul H, Evran S, Çetin D, Suludere Z, Saglam N, Boyaci IH, Tamer U. The coupling of immunomagnetic enrichment of bacteria with paper-based platform. Talanta. 2019;201:245-52.

239. Xie J, Li LY, Khan IM, Wang ZP, Ma XY. Flexible paper-based SERS substrate strategy for rapid detection of methyl parathion on the surface of fruit. Spectrochim Acta A. 2020;231:118104.

240. Liu HY, Zhao P, Wang Y, Li SS, Zhang LN, Zhang Y, Ged SG, Yu JH. Paper-based sandwich type SERS sensor based on silver nanoparticles and biomimetic recognizer. Sens Actuators B Chem. 2020;313:127989.

241. Godoy NV, García-Lojo D, Sigolia FA, Pérez-Juste J, PastorizaSantos I, Mazali IO. Ultrasensitive inkjet-printed based SERS sensor combining a high-performance gold nanosphere ink and hydrophobic paper. Sens Actuators B Chem. 2020;320:128412.

242. Weatherston JD, Seguban RKO, Hunt D, Wu HJ. Low-cost and simple fabrication of nanoplasmonic paper for coupled chromatography separation and surface enhanced raman detection. ACS Sens. 2018:3:852-7.

243. Xiong ZY, Lin MS, Lin HT, Huang MZ. Facile synthesis of cellulose nanofiber nanocomposite as a SERS substrate for detection of thiram in juice. Carbohydr Polym. 2018;189:79-86.

244. Linh VOTN, Moonc J, Muna CW, Devarajd V, Parka JOSG, Kima DH, Choo J, Lee Y, Jung HS. A facile low-cost paperbased SERS substrate for label-free molecular detection. Sens Actuators B Chem. 2019;291:369-77.

245. Sun MZ, Li BH, Liu XJ, Chen JY, Mu TT, Zhu LQ, Guo JH, Ma X. Performance enhancement of paper-based SERS chips by shell-isolated nanoparticle-enhanced raman spectroscopy. Mater J Sci Technol. 2019;35:2207-12.

246. Yang GH, Fang XJ, Jia Q, Gu HX, Li YP, Han CQ, Qu LL. Fabrication of paper-based SERS substrates by spraying silver and gold nanoparticles for SERS determination of malachite green, methylene blue, and crystal violet in fish. Microchim Acta. 2020;187:310.

247. Hassan MM, Jiao TH, Ahmad WQ, Yi X, Zareef M, Ali SJ, Li $\mathrm{HH}$, Chen QS. Cellulose paper-based SERS sensor for sensitive detection of 2,4-D residue levels in tea coupled uninformative variable elimination-partial least squares. Spectrochim Acta A. 2021;248:119198.

248. Lee CW, Chia ZC, Hsieh YT, Tsai HC, Tai Y, Yuc TT, Huang CC. A facile wet-chemistry approach to engineer an Au-based SERS substrate and enhance sensitivity down to ppb-level detection. Nanoscale. 2021;13:3991.

249. Kim HK, Trinh BT, Kim KH, Moon J, Kang H, Jo K, Akter R, Jeong J, Lim E, Jung J, Choi H, Park HG, Kwon OS, Yoon I, Kang T. Au@ZIF-8 SERS paper for food spoilage detection. Biosens Bioelectron. 2021;179:113063.

250. Alder R, Hong J, Chow E, Fang JH, Isa F, Ashford B, Comte C, Bendavid A, Xiao L, Ostrikov K, Fu SL, Murphy ANB. Application of plasma-printed paper-based SERS substrate for cocaine detection. Sensors. 2021;21:810.

251. Park M, Hwang CSH, Orcid KJ. Nanoplasmonic alloy of $\mathrm{Au} / \mathrm{Ag}$ nanocomposites on paper substrate for biosensing applications. ACS Appl Mater Interfaces. 2018;10:290-5.

252. Gao XF, Zheng P, Kasani S, Wu S, Yang F, Lewis S, Nayeem S, Engler-Chiurazzi EB, Wigginton JG, Simpkins JW, Wu NQ. Paper-Based surface-enhanced raman scattering lateral flow strip for detection of neuron-specific enolase in blood plasma. Anal Chem. 2017;89:10104-10.

253. Qi L, Xiao MS, Wang XW, Wang C, Wang LH, Song SP, Qu XM, Li L, Shi JY, Pei H. DNA-encoded raman-active anisotropic nanoparticles for microRNA detection. Anal Chem. 2017;89:9850-6.

254. Sánchez-Purrà M, Carré-Camps M, Bosch I, Gehrke L, HamadSchifferli K. Surface-enhanced raman spectroscopy-based sandwich immunoassays for multiplexed detection of zika and dengue viral biomarkers. ACS Infect Dis. 2017;3:767-76.

255. Russo L, Sánchez-Purrà M, Rodriguez-Quijada C, Leonardo BM, Puntes V, Hamad-Schifferli K. Detection of resistance protein $\mathrm{A}(\mathrm{MxA})$ in paper-based immunoassays with surface enhanced raman spectroscopy with AuAg nanoshells. Nanoscale. 2019;11:10819.

256. Lim WY, Goh C-H, Thevarajah TM, Goh BT, Khor SM. Using SERS-based microfluidic paper-based device $(\mu \mathrm{PAD})$ for calibration-free quantitative measurement of AMI cardiac biomarkers. Biosens Bioelectron. 2020;147:111792.

257. Zou YX, Zhang YL, Xu YT, Chen YQ, Huang SQ, Yu YF, Duan HG, Chen ZC, Tan WH. Portable and label-free detection of blood bilirubin with graphene-isolated-Au-nanocrystals paper strip. Anal Chem. 2018;90:13687-94.

258. Eryılmaza M, Soykutb EA, Çetinc D, Boyacıd İH, Suluderee Z, Tamer U. SERS-based rapid assay for sensitive detection of group a streptococcus by evaluation of the swab sampling technique. Analyst. 2019;144:3573-80.

259. Ying BB, Park S, Chen LY, Dong XK, Young EK, Liu XY. NanoPADs and nanoFACEs: an optically transparent nanopaper-based device for biomedical applications. Lab Chip. 2020;20:3322-33.

260. Hassanaina WA, Izakea EL, Schmidtb MS, Ayokoa GA. Gold nanomaterials for the selective capturing and SERS diagnosis of toxins in aqueous and biological fluids. Biosens Bioelectron. 2017:91:664-72.

261. Li CX, Liu Y, Logo O, Zhou XY, Wang YL. A paper-based SERS assay for sensitive duplex cytokine detection towards the atherosclerosis-associated disease diagnosis. Mater J Chem B. 2020;8:3582-9.

262. Reokrungruang E, Chatnuntawech I, Dharakul T, Bamrungsap S. A simple paper-based surface enhanced raman scattering (SERS) platform and magnetic separation for cancer screening. Sens Actuators B Chem. 2019;285:462-9.

263. Lu D, Ran ML, Liu YF, Xia J, Bi LY, Cao XW. SERS spectroscopy using Au-Ag nanoshuttles and hydrophobic paper-based $\mathrm{Au}$ nanoflower substrate for simultaneous detection of dual 
cervical cancer-associated serum biomarkers. Anal Bioanal Chem. 2020;412:7099-112.

264. Zavyalova E, Ambartsumyan OO, Zhdanov G, Gribanyov OD, Gushchin V, Tkachuk OA, Rudakova E, Nikiforova OM, Kuznetsova ON, Popova L, Verdiev B, Alatyrev A, Burtseva E, Ignatieva A, Iliukhina A, Dolzhikova I, Arutyunyan A, Gambaryan A, Kukushkin V. SERS-Based aptasensor for rapid quantitative detection of SARS-CoV-2. Nanomaterials. 2021;11:1394.

265. Wang DL, Ni HB, Wang ZQ, Liu B, Chen HY, Gu ZZ, Zhao XW. Discrimination of nosiheptide sources with plasmonic filters. ACS Appl Mater Interfaces. 2017;9:13049-55.

266. Pan X, Li LH, Lin HD, Tan JY, Wang HT, Liao ML, Chen CJ. A graphene oxide-gold nanostar hybrid based-paper biosensor for label-free SERS detection of serum bilirubin for diagnosis of jaundice. Biosens Bioelectron. 2019;145:111713.

267. Villa JEL, Pasquini C, Poppi RJ. Surface-enhanced raman spectroscopy and MCR-ALS for the selective sensing of urinary adenosine on filter paper. Talanta. 2018;187:99-105.

268. Han S, Zhang C, Lin S, Sha XY, Hasi WLJ. Sensitive and reliable identification of fentanyl citrate in urine and serum using chloride ion-treated paper-based SERS substrate. Spectrochim Acta A. 2021;251:119463.

269. Gao XF, Boryczka J, Zheng P, Kasani S, Yang F, Engler-Chiurazzi EB, Simpkins JW, Wigginton JG, Wu NQ. A "hot Spot"enhanced paper lateral flow assay for ultrasensitive detection of traumatic brain injury biomarker S-100 $\beta$ in blood plasma. Biosens Bioelectron. 2021;177:112967.

270. Gao XF, Boryczka J, Kasani S, Wu NQ. Enabling direct protein detection in a drop of whole blood with an "on-strip" plasma separation unit in a paper-based lateral flow strip. Anal Chem. 2021;93:1326-32.

271. Li HM, Wang Q, Tang J, Gao NN, Yue XX, Zhong FR, Lv XY, Fu JH, Wang T, Ma CL. Establishment of a reliable scheme for obtaining highly stable SERS signal of biological serum. Biosens Bioelectron. 2021;189:113315.

272. Le HG, Choi W, Yang SY, Kim D, Park S, Lee M, Jung HS. PCRcoupled paper-based surface-enhanced raman scattering (SERS) sensor for rapid and sensitive detection of respiratory bacterial DNA. Sens Actuators B Chem. 2021;326:128802.

273. Hassanzadeh J, Al Lawati HAJ, Lawati IA. Metal-organic framework loaded by rhodamine B as a novel chemiluminescence system for the paper-based analytical devices and its application for total phenolic content determination in food samples. Anal Chem. 2019;91:10631-9.

274. Yahyai IA, Hassanzadeh J, Al-Lawati HAJ. A novel and selective multi-emission chemiluminescence system for the quantification of deltamethrin in food samples. Sens Actuators B Chem. 2021;327:128927.
275. Montali L, Calabretta MM, Lopreside A, D’Elia M, Guardigli M, Michelini E. Multienzyme chemiluminescent foldable biosensor for on-site detection of acetylcholinesterase inhibitors. Biosens Bioelectron. 2020;162:112232.

276. Yang R, Li F, Zhang WC, Shen W, Yang D, Bian ZP, Cui H. Chemiluminescence immunoassays for simultaneous detection of three heart disease biomarkers using magnetic carbon composites and three-dimensional microfluidic paper-based device. Anal Chem. 2019;91:13006-13.

277. Li F, Liu JC, Guo L, Wang JH, Zhang KQ, He JB, Cui H. Highresolution temporally resolved chemiluminescence based on double-layered 3D microfluidic paper-based device for multiplexed analysis. Biosens Bioelectron. 2019;141:111472.

278. Han GR, Ki H, Kim MG. Automated, universal, and mass-producible paper-based lateral flow biosensing platform for highperformance point-of-care testing. ACS Appl Mater Interfaces. 2020;12:1885-9.

279. Liu W, Guo YM, Li HF, Zhao M, Lai ZS, Li BX. A paper-based chemiluminescence device for the determination of ofloxacin. Spectrochim Acta A. 2015;137:1298-303.

280. Liu W, Guo YM, Luo J, Kou J, Zheng HY, Li BX, Zhang ZJ. A molecularly imprinted polymer based a lab-on-paper chemiluminescence device for the detection of dichlorvos. Spectrochim Acta A. 2015;141:51-7.

281. Chu WR, Chen Y, Liu W, Zhao M, Li HF. Paper-based chemiluminescence immunodevice with temporal controls of reagent transport technique. Sens Actuators B Chem. 2017;250:324-32.

282. Chen Y, Chu WR, Liu W, Guo XY, Jin Y, Li BX. Paper-based chemiluminescence immunodevice for the carcinoembryonic antigen by employing multi-enzyme carbon nanosphere signal enhancement. Microchim Acta. 2018;185:187.

283. Chu WR, Chen Y, Liu W, Zhang L, Guo XY. Three-dimensional ring-oven washing technique for a paper-based immunodevice. Luminescence. 2020;35:503-11.

284. Guo XY, Guo YM, Liu W, Chen Y, Chu WR. Fabrication of paper-based microfluidic device by recycling foamed plastic and the application for multiplexed measurement of biomarkers. Spectrochim Acta A. 2019;223:117341.

285. Hou Y, Guo XY, Liu W, Zhang L, Lv CC, Jin Y, Li BX, Peng X, Hang ZX. Paper-based immunosensor with $\mathrm{NH}_{2}$-MIL-53(Fe) as stable and multifunctional signal label for dual-mode detection of prostate specific antigen. J Lumin. 2021;230:117708.

286. Zhang L, Hou Y, Guo XY, Liu W, Lv CC, Peng X, Zhang ZX. Paper-based chemiluminescence device with $\mathrm{Co}-\mathrm{Fe}$ nanocubes for sensitive detection of caffeic acid. Anal Sci. 2021;37:293-9. 